\section{Pacific Northwest}

National Laboratory

Operated by Battelle for the

U.S. Department of Energy

\title{
Evaluating Radionuclide Air Emission Stack Sampling Systems
}

MY Ballinger

December 2002

Prepared for the U.S. Department of Energy under Contract DE-AC06-76RL01830 


\title{
DISCLAIMER
}

This report was prepared as an account of work sponsored by an agency of the United States Government. Neither the United States Government nor any agency thereof, nor Battelle Memorial Institute, nor any of their employees, makes any warranty, express or implied, or assumes any legal liability or responsibility for the accuracy, completeness, or usefulness of any information, apparatus, product, or process disclosed, or represents that its use would not infringe privately owned rights. Reference herein to any specific commercial product, process, or service by trade name, trademark, manufacturer, or otherwise does not necessarily constitute or imply its endorsement, recommendation, or favoring by the United States Government or any agency thereof, or Battelle Memorial Institute. The views and opinions of authors expressed herein do not necessarily state or reflect those of the United States Government or any agency thereof.

\author{
PACIFIC NORTHWEST NATIONAL LABORATORY \\ operated by \\ BATTELLE \\ for the \\ UNITED STATES DEPARTMENT OF ENERGY
}

under Contract DE-AC06-76RL01830

Printed in the United States of America

Available to DOE and DOE contractors from the

Office of Scientific and Technical Information,

P.O. Box 62, Oak Ridge, TN 37831-0062;

ph: (865) 576-8401

fax: (865) 576-5728

email: reports@adonis.osti.gov

\begin{abstract}
Available to the public from the National Technical Information Service, U.S. Department of Commerce, 5285 Port Royal Rd., Springfield, VA 22161 ph: (800) 553-6847 fax: (703) 605-6900

email: orders@ntis.fedworld.gov

online ordering: http://www.ntis.gov/ordering.htm
\end{abstract}

This document was printed on recycled paper.

$(8 / 00)$ 


\title{
Evaluating Radionuclide Air Emission Stack Sampling Systems
}

\author{
Marcel Y Ballinger \\ A thesis submitted in partial fulfillment of the \\ requirements for the degree of \\ Master of Science in Engineering
}

University of Washington

2002

Program Authorized to Offer Degree: College of Engineering 


\title{
University of Washington
}

Graduate School

This is to certify that I have examined this copy of a master's thesis by

\author{
Marcel Y Ballinger
}

and have found that it is complete and satisfactory in all respects, and that any and all revisions required by the final examining committee have been made.

Committee Members:

Timothy Larson

Michael Pilat

Date: 
In presenting this thesis in partial fulfillment of the requirements for a Master's degree at the University of Washington, I agree that the Library shall make its copies freely available for inspection. I further agree that extensive copying of this thesis is allowable only for scholarly purposes, consistent with "fair use" as prescribed in the U.S. Copyright Law. Any other reproduction for any purposes or by any means shall not be allowed without my written permission.

Signature

Date 
University of Washington

\title{
Abstract \\ Evaluating Radionuclide Air Emission Stack Sampling Systems
}

\author{
Marcel Y Ballinger \\ Chair of the Supervisory Committee: Professor Timothy Larson \\ Department of Civil and Environmental Engineering
}

The Pacific Northwest National Laboratory (PNNL) operates a number of research and development (R\&D) facilities for the U.S. Department of Energy at the Hanford Site, Washington. These facilities are subject to Clean Air Act regulations that require sampling of radionuclide air emissions from some of these facilities. A revision to an American National Standards Institute (ANSI) standard on sampling radioactive air emissions has recently been incorporated into federal and state regulations and a re-evaluation of affected facilities is being performed to determine the impact. The revised standard requires a well-mixed sampling location that must be demonstrated through tests specified in the standard. It also carries a number of maintenance requirements, including inspections and cleaning of the sampling system. Evaluations were performed in $2000-2002$ on two PNNL facilities to determine the operational and design impacts of the new requirements. The evaluation included inspection and cleaning maintenance activities plus testing to determine if the current sampling locations meet criteria in the revised standard.

Results show a wide range of complexity in inspection and cleaning activities depending on accessibility of the system, ease of removal, and potential impact on building operations (need for outages). As expected, these High Efficiency Particulate Air (HEPA)-filtered systems did not show deposition significant enough to cause concerns with blocking of the nozzle or other parts of the system. The tests for sampling system location in the revised standard also varied in complexity depending on accessibility of the sample site and use of a scale model can alleviate many issues. Previous criteria to locate sampling systems at eight duct diameters downstream and two duct diameters upstream of the nearest disturbances is no guarantee of meeting criteria in the revised standard. A computational fluid dynamics model was helpful in understanding flow and contaminant mixing in an exhaust system and may be useful to identify potential sampling locations in an exhaust system that are likely to meet criteria in the revised standard. 


\section{TABLE OF CONTENTS}

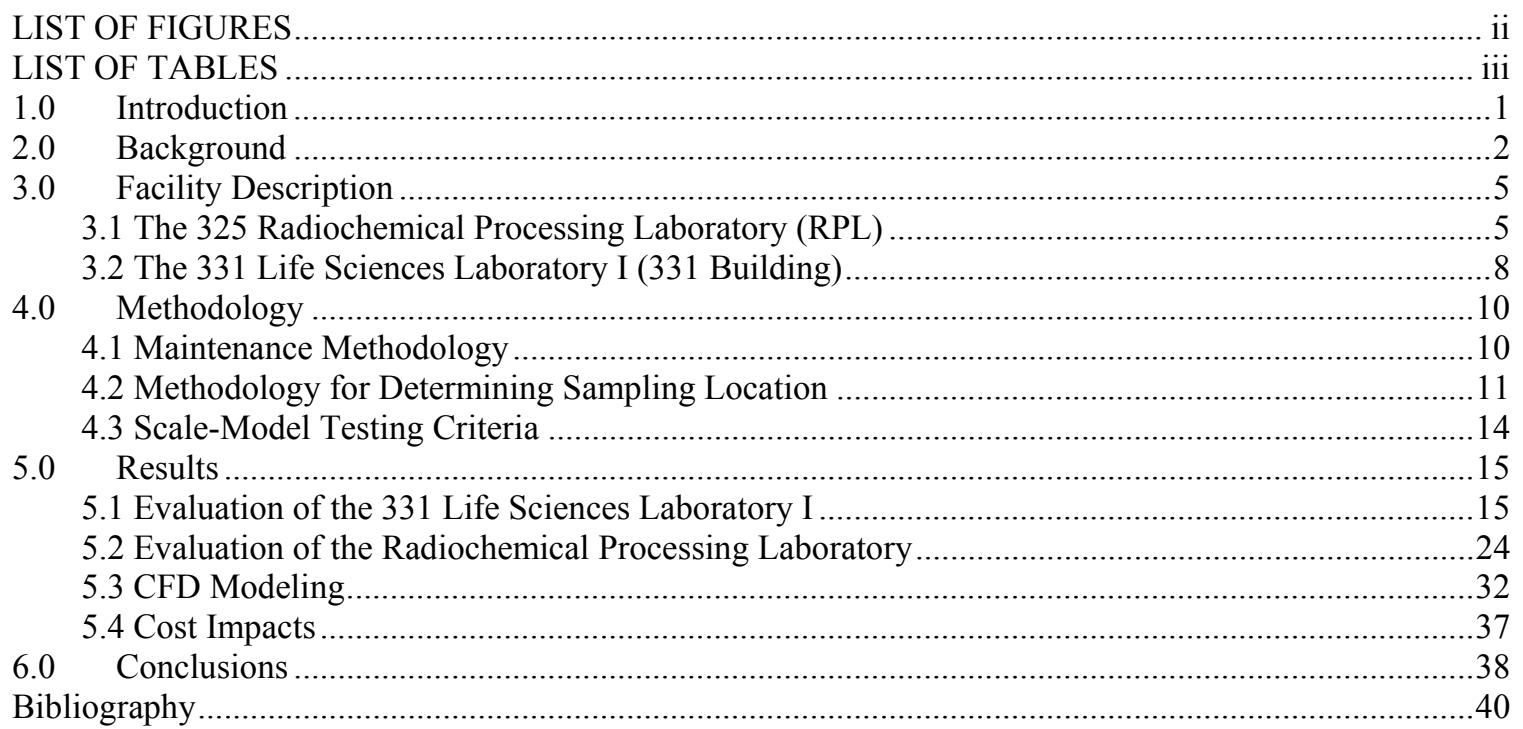




\section{LIST OF FIGURES}

$\begin{array}{ll}\text { Figure Number } & \text { Page }\end{array}$

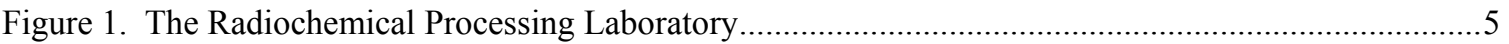

Figure 2. Radiochemical Processing Laboratory Main Stack..........................................................................

Figure 3. RPL Sampling Manifold Bundle ..........................................................................................



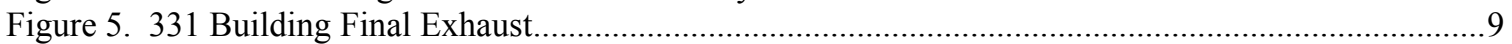

Figure 6. Shrouded Probe Design (Figure 2 in ANSI/HPS N13.1 - 1999) ...............................................10

Figure 7. Inside of 331 Radionuclide Air Sampling System Manifold ........................................................16

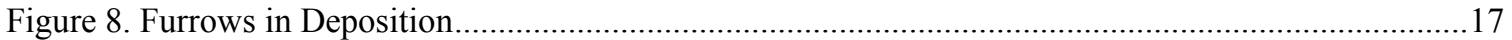

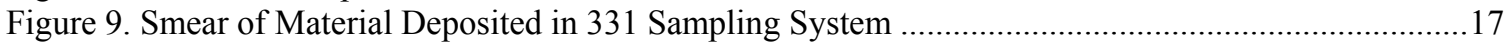



Figure 11. Scanning Electron Microscope Photograph of Smear Material .................................................19

Figure 12. Energy Dispersive Spectrometry Analysis..............................................................................19

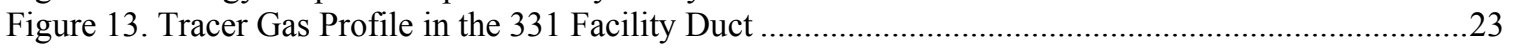



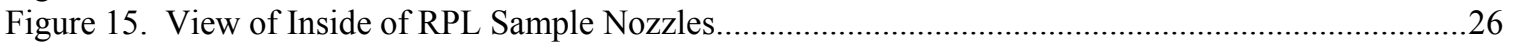

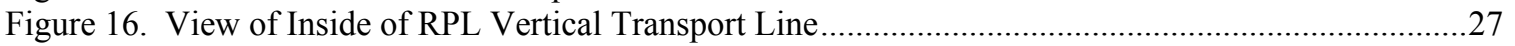

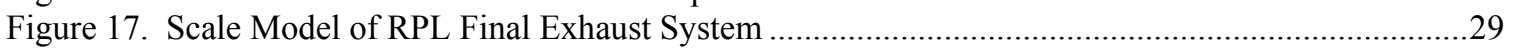

Figure 18. Injection Locations for Gas and Aerosol Tracer Tests............................................................ 31

Figure 19. Tracer Aerosol Profile in the 325 Facility Proto-type Stack .....................................................33

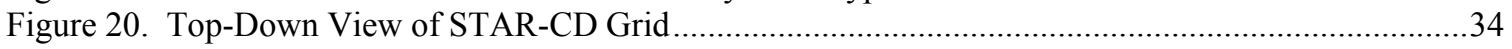



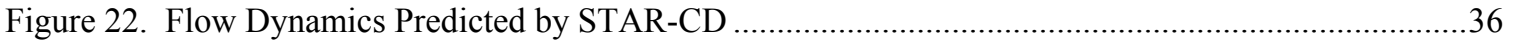




\section{LIST OF TABLES}

Table Number

Page

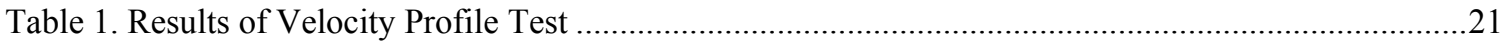

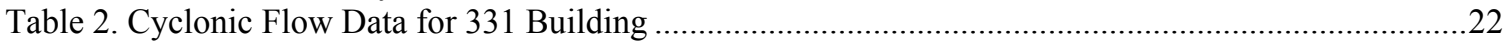

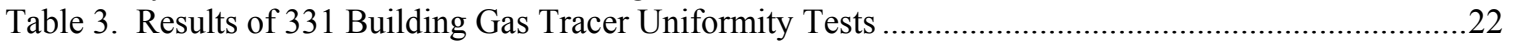



Table 5. Velocity Profile Test Results for RPL Prototype …..................................................................

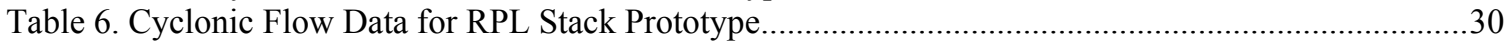

Table 7. Results of 331 Building Gas Tracer Uniformity Tests ................................................................32

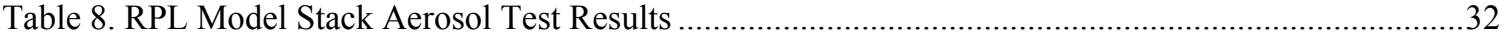

Table 9. Comparison of CFD Predictions with Measured Values...................................................................34

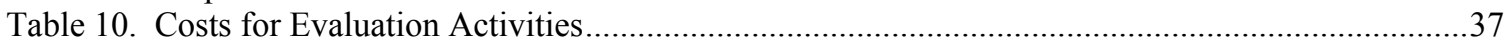




\subsection{Introduction}

The Pacific Northwest National Laboratory (PNNL) operates a number of research and development (R\&D) facilities for the U.S. Department of Energy at the Hanford Site, Washington. Some of the projects conducted in these facilities involve the use of radioactive materials; thus, the facilities are subject to federal and state regulations requiring the sampling of radioactive air emissions. In the past, these regulations incorporated by reference American National Standards Institute (ANSI) N13.1-1969 Guide to Sampling Airborne Radioactive Materials in Nuclear Facilities. The ANSI standard was updated in 1999 and the revised version, Sampling and Monitoring Releases of Airborne Radioactive Substances from the Stacks and Ducts of Nuclear Facilities, provides performance-based criteria for radionuclide air sampling systems rather than the prescriptive criteria in the initial version. Federal regulations have been amended to apply the revised standard to new emission units and to require preventative maintenance activities to currently operating emission points with a potential for significant emissions $(>1 \%$ of the standard). In addition, Washington State regulations have started applying requirements from the revised standard on a case-by-case basis as permitting modifications are approved.

Application of the revised standard may present operational and/or design issues for the radionuclide air sampling systems at PNNL facilities. These systems were designed to comply with ANSI N13.1-1969 and the design may be incompatible with the revised standard. Also, the systems were not designed for some of the annual maintenance and inspection activities that may now be required, making these activities difficult and costly to perform. An evaluation of the sampling systems at PNNL's two most significant emission units was conducted to determine the impact of requirements in the revised standard on the design and operation of the systems. This paper documents the results of those evaluations. 


\subsection{Background}

Clean Air Act regulations were enacted by the federal government to improve air quality in the United States. Included in these regulations are the National Emission Standards for Hazardous Air Pollutants (NESHAP) which apply to radioactive airborne emissions in addition to emissions of other hazardous materials. The radionuclide NESHAP is codified in the Code of Federal Regulations (CFR) Title 40 Part 61 (US EPA 1990). Subpart H of 40 CFR 61 regulates radioactive emissions from the United States Department of Energy (DOE) facilities including those at the Hanford Site in Washington State. DOE-owned, PNNL-operated R\&D facilities on the Hanford Site must meet the radionuclide NESHAP requirements.

The State of Washington also regulates radioactive air emissions on the Hanford Site through Washington Administrative Code (WAC) 246-247 Radiation Protection - Air Emissions. The state regulations reflect federal regulations, but can be more stringent if the state chooses.

Both the federal and state regulations incorporated ANSI N13.1 Guide to Sampling Airborne Radioactive Materials in Nuclear Facilities by reference. In the EPA regulation (40 CFR 61) the original 1969 standard is referenced by date; in the state regulation, no date is given. PNNL facilities at Hanford with radionuclide air emission sampling systems complied with the 1969 standard. ANSI N13.1 was revised in 1999 and renamed Sampling and Monitoring Releases of Airborne Radioactive Substances from the Stacks and Ducts of Nuclear Facilities. The revised standard takes a drastically different approach than the initial version. Instead of a multi-nozzle isokinetically operated sampling system located a minimum of five duct diameters downstream of abrupt changes in flow direction or prominent transitions, the revised standard calls for single-point sampling in a well-mixed location. The sampling location must be tested and meet criteria specified in the standard. In addition, the revised standard specifies a number of maintenance activities including annual inspections of the sampling system and potential cleaning based on inspection results. PNNL conducted an evaluation over the $2000-2002$ time period to determine the impacts of these new requirements on the most significantly affected PNNL facilities.

During this same time period, federal and state regulators were deciding on the most appropriate application of the revised standard. In September 2002, EPA amended 40 CFR 61 (Federal Register 2002) to require use of the revised standard for new emission units with potential radioactive airborne emissions in excess of $1 \%$ of the standard ${ }^{1}$, often referred to as "major" emission points. The potential-to-emit is calculated using methods specified in the regulation and do not take credit for facility emission controls, typically High Efficiency Particulate Air (HEPA) filtration. Major emission points are required to be

\footnotetext{
${ }^{1}$ The standard given in 40 CFR 61 Subpart $\mathrm{H}$ is $10 \mathrm{mrem} / \mathrm{year}$, so major emission points are those with a potential-to-emit of $>0.1 \mathrm{mrem} /$ year if emission controls were not applied.
} 
sampled continuously whereas sampling for "minor" emission points can be done on a periodic confirmatory basis. In addition to requiring ANSI/HPS N13.1 - 1999 for new or significantly modified major emission points, the maintenance requirements in the revised standard were incorporated into the quality assurance sections of 40 CFR 61 Appendix B, Reference Method 114 Test Methods for Measuring Radionuclide Emissions from Stationary Sources. These quality assurance sections are required for major emission points and are applicable to all major systems, including those currently operating under and compliant with the initial 1969 standard.

The state did not amend the revised standard into WAC 246-247, but instead took the position that an amendment was not required because ANSI N13.1 was cited without specifying the version date. The state has started applying requirements from the revised standard on a case-by-case basis as permitting modifications are approved. The state has not limited the application of new requirements to major emission points, but has also applied some aspects to minor emission points. However, the state has not yet required currently operated systems to be upgraded to ANSI/HPS N13.1 - 1999 standards unless they are significantly modified.

PNNL currently has three major and more than a dozen minor emission points registered with the state. The Washington State Department of Health has been delegated enforcement authority for federal and state radionuclide NESHAP regulations. The three major emission points are for the following facilities: 1) the 325 Radiochemical Processing Laboratory (RPL), 2) the 331 Life Sciences Laboratory I, and 3) the 3720 Environmental Sciences Laboratory. These emission points are sampled continuously for radioactive materials and comply with all federal and state requirements previous to the amendments. A gap analysis is currently underway to determine any additional activities needed to comply with newly amended requirements.

The evaluations conducted in $2000-2002$ were focused on the emission points for the RPL and 331 Buildings because these facilities are expected to be the most severely impacted; future plans for the 3720 Building are uncertain, but may include shut down of the facility. In 2000, tests were conducted to assess the mixing characteristics at the 331 Building main stack sampling location to determine if they met criteria in ANSI/HPS N13.1 - 1999. A remote camera inspection of the 331 Building followed in 2001, with subsequent cleaning of the 331 sampling system in 2002. An evaluation of the RPL main stack was conducted in 2002, including a remote camera inspection and mixing tests performed on a scale-model version of the RPL exhaust system. The scale-model tests also included use of a computational fluid dynamics code to predict flow dynamics and contaminant mixing in the system and predict measurement results at the sampling location. The following sections describe the buildings evaluated, discuss the methods used, and provide results of the evaluations.

\footnotetext{
${ }^{2}$ Minor emission points are those that could potentially release radionuclides, but with less dose impact
} 
than a major emission point. 


\subsection{Facility Description}

The radionuclide airborne sampling systems for two PNNL-operated facilities were evaluated against requirements in ANSI/HPS N13.1 - 1999 Sampling and Monitoring Releases of Airborne Radioactive Substances from the Stacks and Ducts of Nuclear Facilities. These facilities were chosen for evaluation because they have the highest potential-to-emit of the PNNL facilities, possess major emission points that are required to be continuously monitored, have ongoing missions that are likely to continue to involve significant amounts of radioactive materials, and are the most likely to be affected by the regulatory changes incorporating aspects of the revised standard. The sections below give a brief description of the building, activities, and sampling system for each of the facilities evaluated.

\subsection{The 325 Radiochemical Processing Laboratory (RPL)}

The RPL was designed and constructed in the 1950s to safely perform research and development work with high levels of radioactive materials (Gerber 1992). The three story building (see Figure 1) has over 140,000 total square feet with over 100 offices, more than 70 individual laboratories, and specialized areas such as high bays, hot cells, shops, and waste treatment operations.

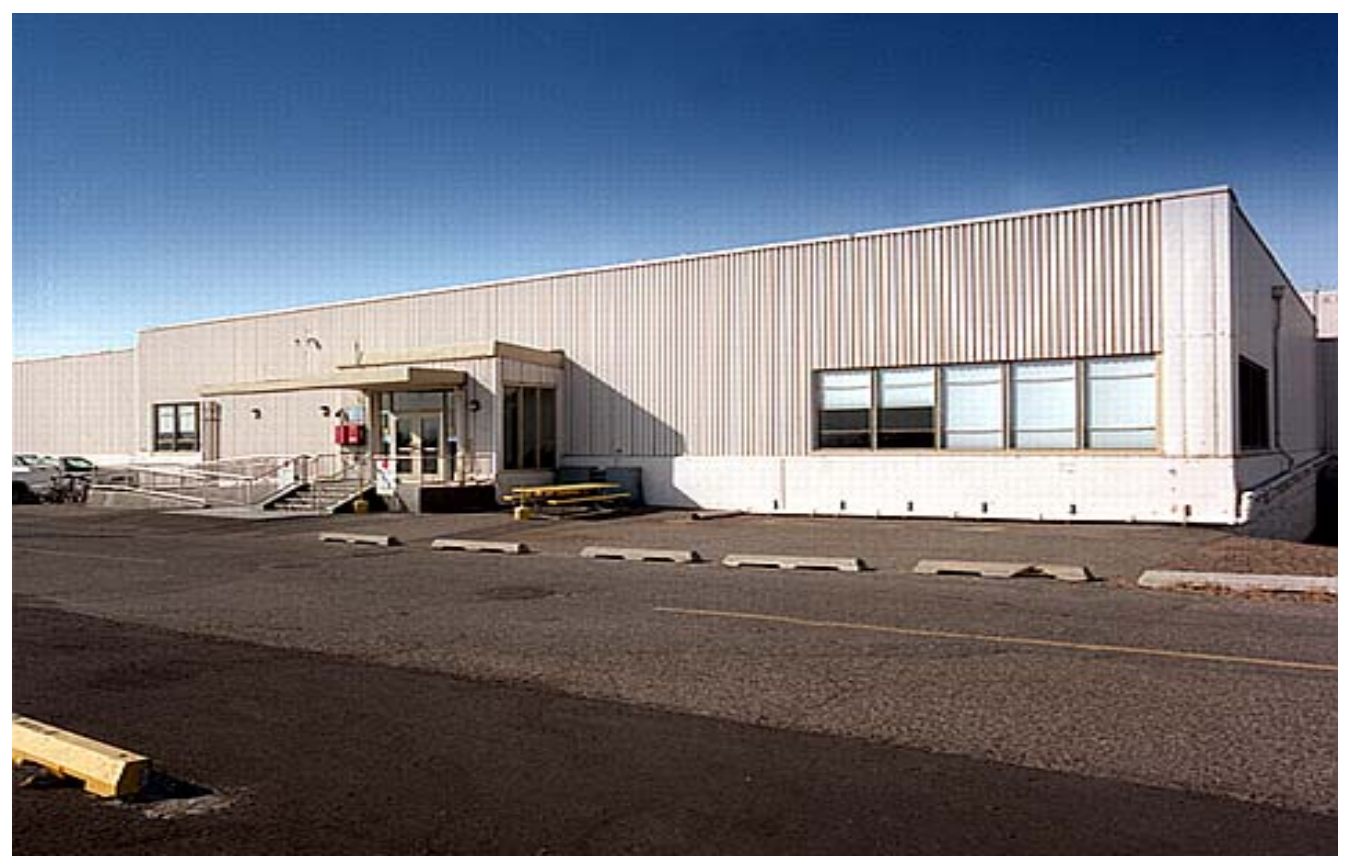

Figure 1. The Radiochemical Processing Laboratory 
The current mission of the RPL is to create and implement innovative processes for environmental clean-up and the beneficial use of radioactive materials. This includes processes to advance the cleanup of radiological and hazardous wastes; the processing and disposal of nuclear fuels; and the production and delivery of medical isotopes. Because the RPL is an R\&D facility, individual projects conducted in the facility frequently change. The inventory of radioactive material in the building also changes, but can include microgram to kilogram quantities of fissionable materials, and up to megacurie quantities of other radionuclides. A potential-to-emit is calculated annually based on the inventory of radioactive material in the building using methods and release fractions from 40 CFR 61 Appendix D. Per regulations, the potential-to-emit is calculated without taking credit for emission controls (Ballinger et. al., 2001). The potential-to-emit for RPL exceeds 1\% of the standard in 40 CFR 61 Subpart $\mathrm{H}$ and the stack is classified as a major emission point that must be continuously monitored for radionuclide airborne emissions. The potential-to-emit also exceeds $50 \%$ of the standard and thus would be classified under the highest Potential Impact Category (PIC) in ANSI/HPS N13.1 - 1999. The revised standard introduces PIC categories to establish a graded approach to sampling and monitoring requirements. Actual emissions for 2001 were reported as $0.12 \mathrm{mrem}$, almost all of which is from tritium emissions conservatively assumed to be in the form of tritiated water (Rokkan et. al., 2002).

The RPL emission point exhausts air from all areas of the building where radioactive materials are handled. The exhaust stream passes through HEPA filters located just upstream of the exhaust fans. The stack (see Figure 2) is 89-feet tall and 8-feet in diameter. Stack flows are approximately 140,000 cubic feet per minute (cfm). The sampling system is located about 80 feet above the ground (see the platform in Figure 2).

The sampling system is composed of a six-nozzle probe rake and an approximately 60 -foot long sample transport line leading down the stack to a sample cabinet on the third floor of the RPL. The sample cabinet location is conveniently located for frequent sample collection. The particulate sampling system manifold is bundled together with a continuous air-monitoring manifold (see Figure 3). The entire bundle allows for continuous sampling and monitoring of radioactive particles and tritium. The manifold is heavy, requiring the use of a counterweight and crane for installation or removal. The system is compliant with ANSI N13.1 - 1969. More details on the facility and sampling system can be obtained from the Facility Effluent Monitoring Plan for the 325 Radiochemical Processing Laboratory (Ballinger 2001). 


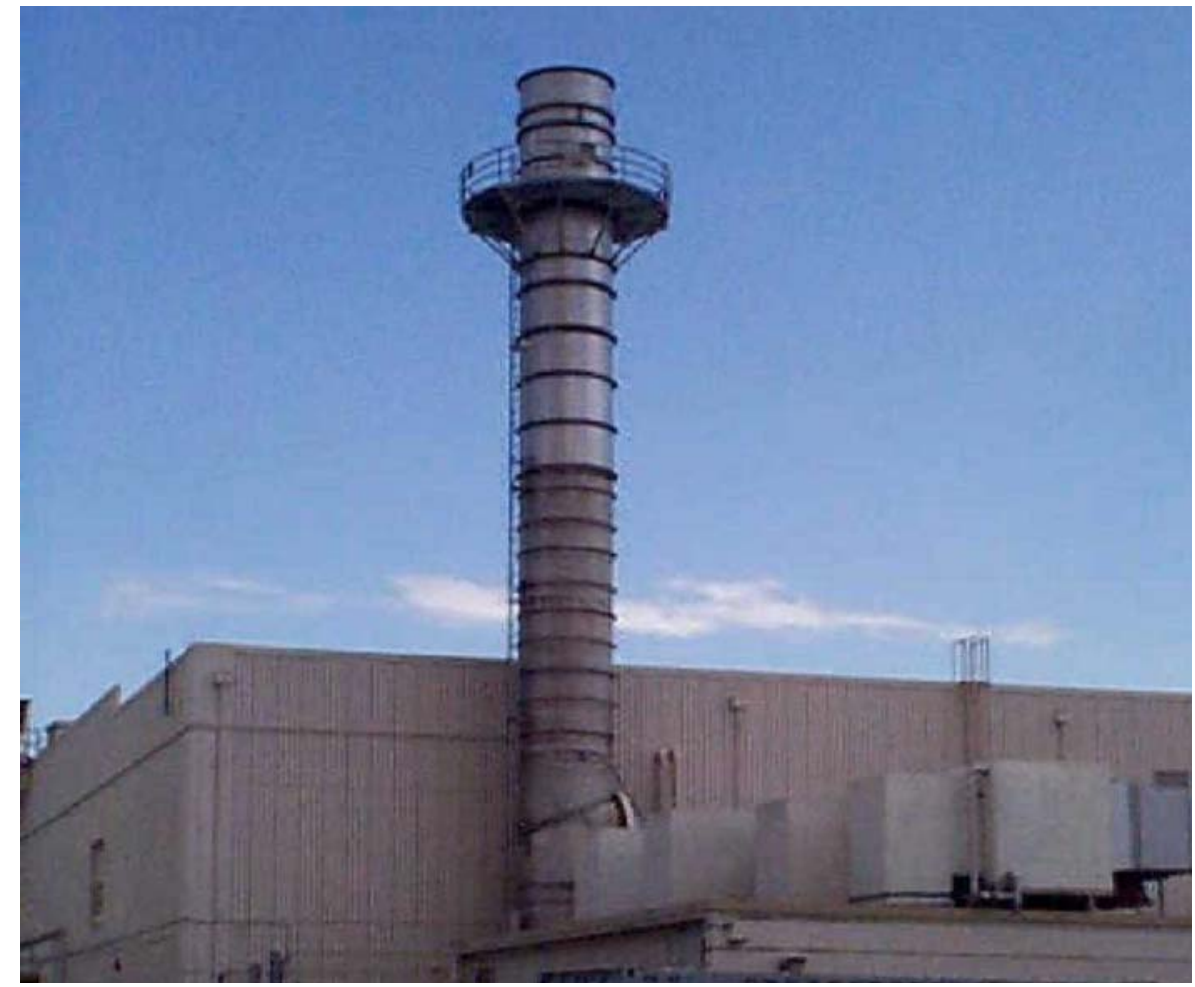

Figure 2. Radiochemical Processing Laboratory Main Stack

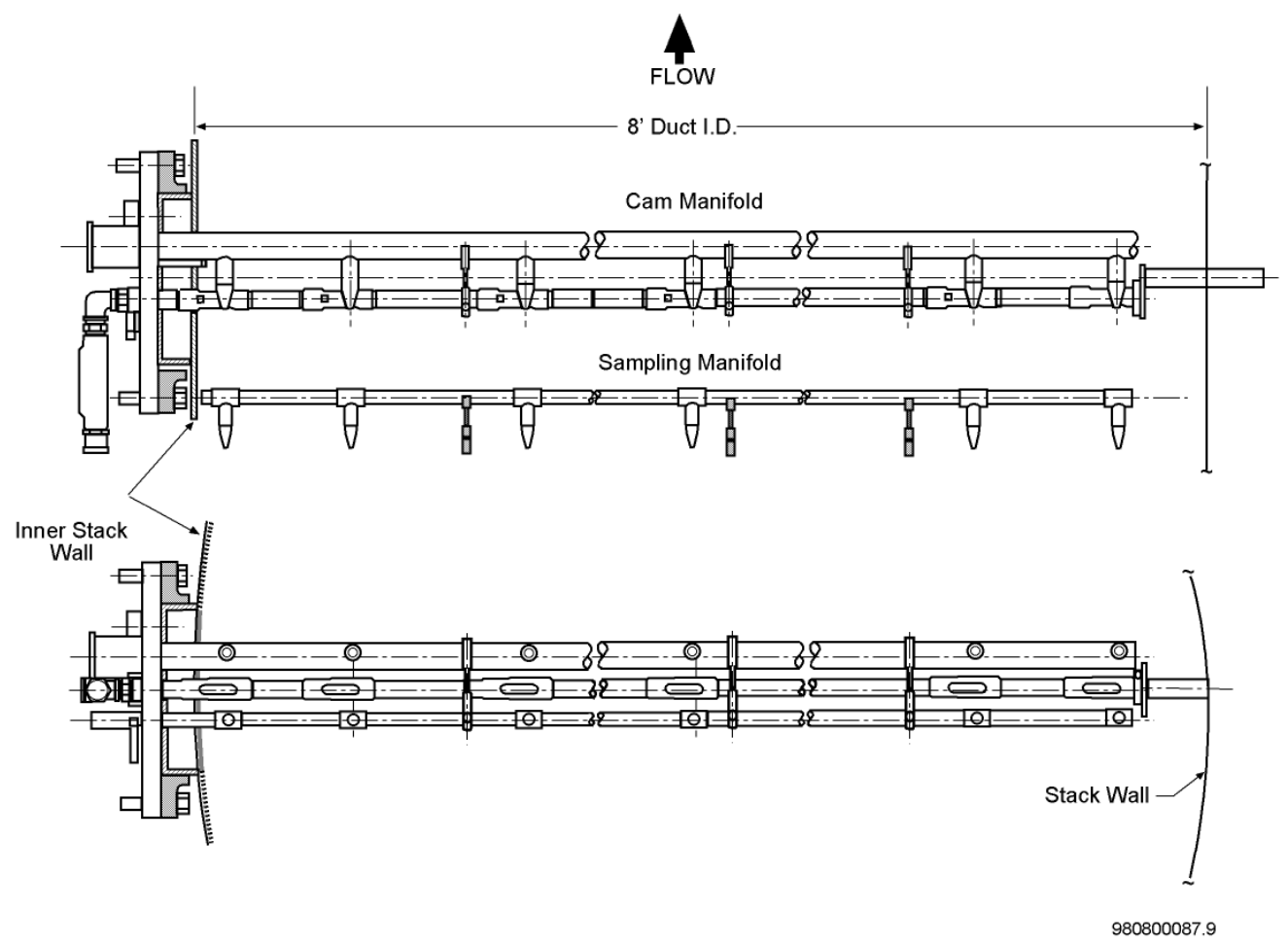

Figure 3. RPL Sampling Manifold Bundle 


\subsection{The 331 Life Sciences Laboratory I (331 Building)}

The 331 Building was constructed in 1970 to accommodate a wide variety of biological and ecological research studies (Gerber 1992). The three story building has over 115,000 total square feet with over 100 offices, more than 70 individual laboratories, and specialized areas such as a number of animal rooms, photo labs, a hot cell, and a shop (see Figure 4). Currently, the 331 Building provides research capabilities to study the health effects of chemicals and radiation and the uptake and transformation effects in soils, plants, animals, microorganisms, and solutions when they are exposed to radiation. The facility is designed to accommodate the use of radioactive and hazardous materials to conduct these activities. Because the 331 Building is an R\&D facility, individual projects conducted in the facility frequently change. The inventory of radioactive material in the building also changes, but can include gram quantities of fissionable materials, and up to curie quantities of other radionuclides. The main stack for the 331 Building is currently registered as a major emission point that must be continuously monitored for radioactive airborne emissions. This emission point would be considered PIC 2 under the ANSI/HPS N13.1 - 1999 classification criteria. Actual emissions for 2001 were reported to be 6.6E-5 mrem (Rokkan et. al., 2002).

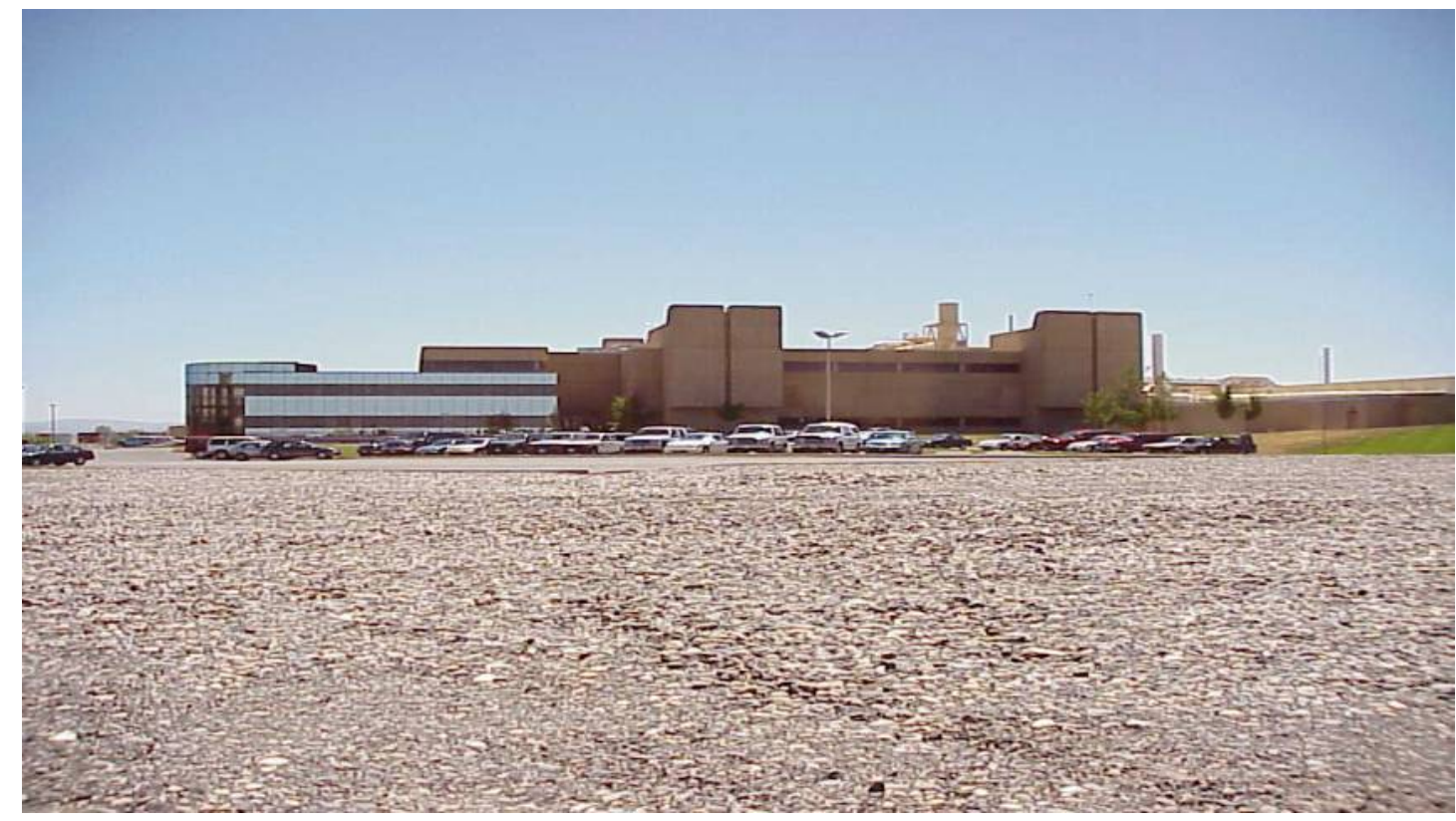

Figure 4. The 331 Building Life Sciences Laboratory 
The 331 Building main stack emission point exhausts air from all areas of the building where dispersible $^{3}$ radioactive materials are handled. The exhaust ventilation runs horizontally on the roof of the 331 Building before bending vertically to an exhaust point (see Figure 5). The exhaust duct is 6.5 feet in diameter with a flow of approximately $70,000 \mathrm{cfm}$. The sampling system, which is much more accessible than the RPL, is located on the horizontal length of duct and meets the criteria in 40 CFR 60 Appendix A, Reference Method 1 for sampling at least eight duct diameters downstream and two diameters upstream from any flow disturbances. The sampling system is composed of a six-nozzle probe connected to a short sample transport line connected to a sample cabinet on the roof. The system is compliant with ANSI N13.1 - 1969. More details on the facility and sampling system can be obtained from the Facility Effluent Monitoring Plan for the 331 Radiochemical Complex (Ballinger 2002).

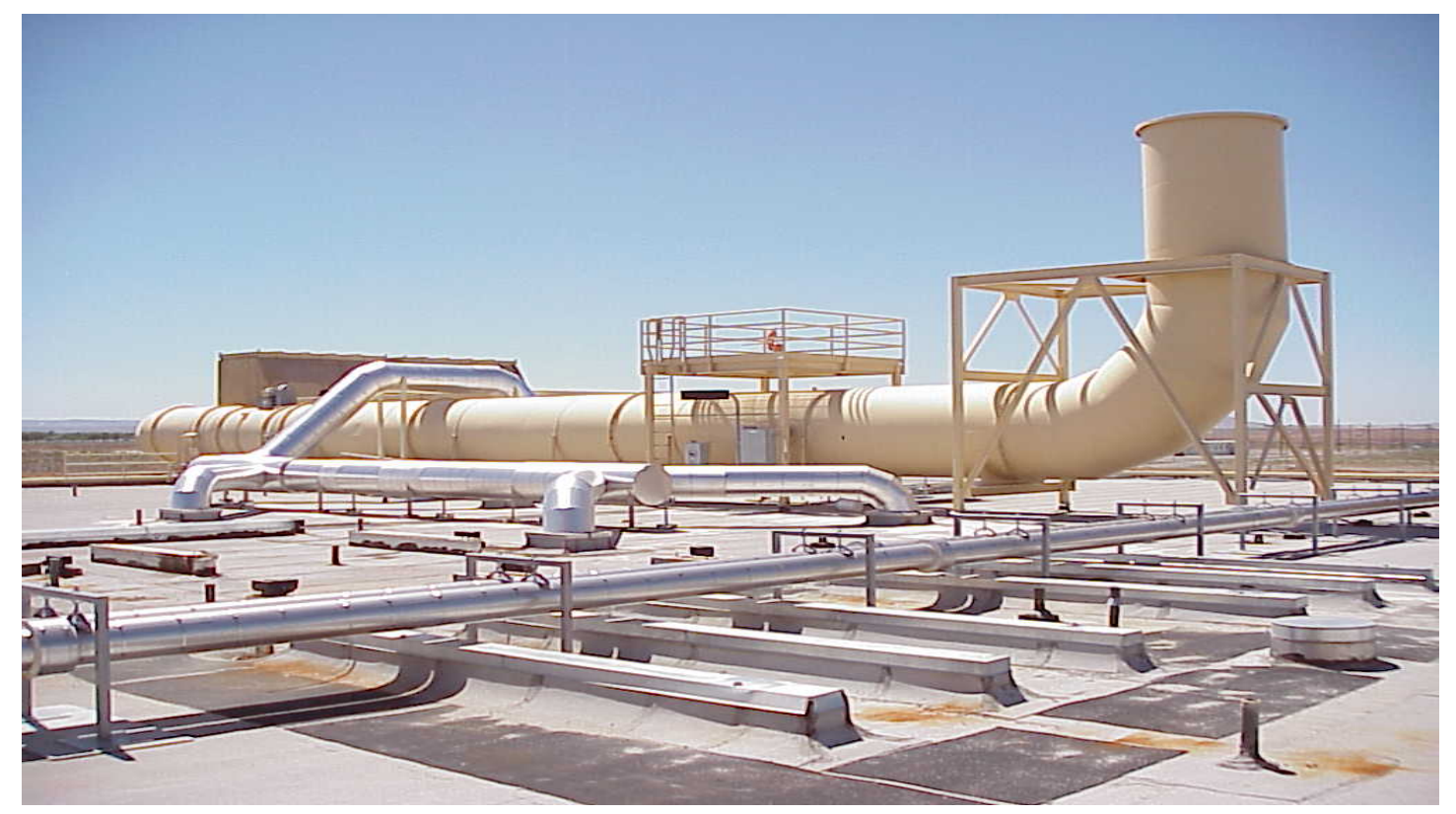

Figure 5. 331 Building Final Exhaust

\footnotetext{
${ }^{3}$ The 331 Building has emission points other than the main stack and areas exhausting to these other emission points may contain sealed radioactive sources with no emission potential.
} 


\subsection{Methodology}

Methods used in the evaluation of the RPL and 331 Building radionuclide air sampling systems are governed by ANSI/HPS N13.1 - 1999 Sampling and Monitoring Releases of Airborne Radioactive Substances from the Stacks and Ducts of Nuclear Facilities. Pertinent methods relating to requirements for inspection and cleaning of systems for sampling radioactive aerosols are discussed in Section 4.1; methods relating to testing and acceptance criteria for proving out a sampling location for radioactive airborne particles are discussed in Section 4.2. A scale-model was used to test the sampling system location for the RPL; in-place testing is difficult to perform at the actual sampling location because it is elevated eighty feet above the ground and because of the possible disruptions to operations in this nuclear facility. ANSI/HPS N13.1 - 1999 allows for scale-model testing if it meets specific criteria discussed in Section 4.3.

\subsection{Maintenance Methodology}

The revised ANSI/HPS N13.1 - 1999 requires particulate material sampling probes to have nozzles with sharp edges. The only exception is the shroud on a shrouded probe design (see Figure 6), which should not have a sharp leading edge. A shrouded probe nozzle is recommended in the revised standard because the particle losses to the walls of the probe are greatly reduced over unshrouded probes, particularly for larger particle sizes. The revised standard assumes a default particle size of $10 \mu \mathrm{m}$ aerodynamic diameter ${ }^{4}$ for design and testing of a sampling system unless a larger particle size is known to be present. A visual inspection of the nozzle edge is called for following installation, annually, and after any maintenance has been performed to verify that no damage has occurred.



Figure 6. Shrouded Probe Design (Figure 2 in ANSI/HPS N13.1 - 1999)

\footnotetext{
${ }^{4}$ The aerodynamic diameter of a particle of arbitrary shape and density is the diameter of a spherical water droplet that has the same sedimentation velocity in quiescent air as the arbitrary particle.
} 
Nozzles are to be inspected annually to check for alignment and potential blocking or other damage. In dusty environments, background aerosols can block nozzle openings, reducing sampling effectiveness. ANSI/HPS N13.1 - 1999 calls for sufficient cleaning in these environments to make sure that not more than five percent of the nozzle opening can become blocked. The revised standard acknowledges that HEPA-filtered environments are expected to be relatively clean; for these environments, the nozzle should be cleaned "if there are visible deposits of material on either the internal or external regions of the nozzle" (Section 6.3.4.8 of ANSI/HPS N13.1 - 1999). If deposits are indicated inside the nozzle during an annual inspection, the inspection should be broadened to cover the interior of the transport lines (Section 6.4.6 of ANSI/HPS N13.1 - 1999) and the transport lines should be cleaned if deposits are visible in the lines. For non-HEPA-filtered environments with background aerosols, two options are provided:

- Estimate the rate of deposition and clean the internal walls when the mean mass exceeds 1 $\mathrm{g} / \mathrm{m}^{2}$.

- $\quad$ Based on system performance, clean the transport lines so that the overall penetration of 10 $\mu \mathrm{m}$ aerodynamic diameter particles is not reduced by more than $10 \%$.

The term "visible" is not defined in the standard.

\subsection{Methodology for Determining Sampling Location}

In the revised ANSI/HPS N13.1 - 1999 standard, a multi-nozzle sampling rake is discouraged because wall losses of particles can be unacceptably high for larger particles (up to $10 \mu \mathrm{m}$ aerodynamic diameter. Instead, single-point sampling is to be used at a location that is shown to be well-mixed. The testing methods and acceptance criteria for the sampling location are given in sections 5.2 and 5.3 and summarized in Table 4 of ANSI/HPS N13.1 - 1999. Tests must be conducted to address the potential for cyclonic flow, air velocity uniformity, gas concentration uniformity, and aerosol concentration uniformity. The following paragraphs describe each of these concerns and the measurements required to determine whether the location is acceptable.

\subsubsection{Cyclonic Flow}

Sampling nozzles are usually aligned with the axis of the stack. If the air travels up the stack in cyclonic fashion, the air velocity vector approaching the nozzle could be misaligned with the sampling nozzles enough to impair the extraction of particles. The flow angle is measured in the stack at the elevation of the sampling nozzle. The average air-velocity angle must not deviate from the axis of the sampling nozzle by more than 20 degrees. 
The test method is based on 40 CFR 60, Appendix A, Reference Method 1, Section 2.4, Verification of the Absence of Cyclonic Flow. The flow angle is measured at a grid of points in a crosssection of the stack at the location of the sampling probe. The grid is an array of points in an x-pattern. One line of points is aligned in the same direction as the existing sampling probe on the actual stack; the other line is perpendicular to that. The number and distance between measurement points is based on the EPA procedure 40 CFR 60, Appendix A, Reference Method 1 Sample and Velocity Traverses for Stationary Sources. Measurements are made using a type-S pitot tube, a slant tube or electronic manometer, and a protractor level or angle-indicating device attached to the pitot tube.

\subsubsection{Velocity Uniformity of Stack Gas}

It is important that the gas momentum across the stack cross-section where the sample is extracted be well mixed or uniform. Consequently, the velocity is measured at several points in the stack at the elevation of the sampling nozzle. The uniformity is expressed as the variability of the measurements about the mean. This is expressed using the relative coefficient of variance (COV), which is the standard deviation divided by the mean and expressed as a percentage. The lower the COV value, the more uniform the velocity. The acceptance criterion is that the COV of the air velocity must be $\leq 20 \%$ across the center two-thirds of the area of the stack. To determine uniformity, air velocity is measured at the same grid of

points used for the angular flow test described previously. The equipment includes a standard Prandtl-type or S-type pitot tube and a calibrated electronic manometer or a slant tube manometer.

\subsubsection{Gas Tracer Uniformity}

A uniform contaminant concentration in the sampling plane enables the extraction of samples that represent the true concentration. This is first tested using a tracer gas to represent gaseous effluents. The gas must be injected downstream of the last location where source radioactive airborne emissions can be introduced. This location can be upstream of a final fan. However, if the aerosol tracer uniformity test must also be performed (because the system is sampling for particles), the more stringent criteria for aerosol injection location ("downstream of feeder ducts, fans, and air pollution control equipment," Section 5.3 of ANSI/HPS N13.1 - 1999) should be used for both sets of tests.

Injection of tracer gas is required at five or more locations across the cross-section of the air stream. For a circular duct, these locations can be the center of the duct and near (within $20 \%$ of a diameter) the wall at four equidistant locations. The tracer gas must be sampled at the cross-sectional plane of the sampling location in the same grid used for the other tests (40 CFR 60 Appendix A Reference Method 1). The test will be repeated for the injection point found to have the least favorable result. The 
acceptance criteria are that: 1 ) the COV of the measured tracer gas concentration is $\leq 20 \%$ across the center two-thirds of the sampling plane, and 2) at no point in the sampling plane does the concentration vary from the mean by $>30 \%$.

Gas concentration is measured with a gas analyzer calibrated for the tracer gas. Sulfur hexafluoride (SF6) was used as the tracer gas for the PNNL experiments. An estimate of total SF6 emissions was made prior to testing to verify that no air chemical emission limits would be exceeded. The absolute calibration of the analyzer is unimportant to the test results because the criteria are for variability in concentration; however, the analyzer response is checked using calibration standards prior to the conduct of the test. If the indicated concentration is within $20 \%$ of the standard, the response is acceptable.

\subsubsection{Particle Tracer Uniformity}

Uniformity in contaminant concentration at the sampling elevation is further demonstrated using tracer particles large enough to exhibit inertial effects. Particles of $10-\mu \mathrm{m}$ aerodynamic diameter are used by default unless it is known that larger particles are present in the airstream.

The test for uniformity of tracer particles is similar to the test for uniformity of tracer gases. The general approach is to inject particles of a range of sizes, including the size of interest, into the center of the airstream. The concentration of the particles of the size range of interest is then measured at several points in the cross-section of the sampling plane using a calibrated optical particle counter (OPC). A simple probe is used to extract the sample and deliver a sample of the airstream to the OPC.

Particles are manufactured by spraying vacuum-pump oil through a nozzle housed in a chamber, which provides a controlled means for injecting the particles into the airflow through a probe. Compressed air and an injection probe are required for the operation of the chamber. The location of the aerosol tracer injection port is the same as for the gaseous tracer; however, per the 1999 standard, only a centerline injection position is required. The layout of measurement points at the sample location is the same as for all of the other tests.

The OPC sorts the number of particles into six size channels. Each concentration reading is the count of particles collected in the 9- to 11- $\mu$ m channel. The readings are recorded on a data sheet. Three readings are taken at each point and averaged. The coefficient of variance of the average concentration readings at all points is calculated and the result compared to the acceptance criterion for uniformity. The particle mixing is acceptable if the COV of the tracer particles of $10-\mu \mathrm{m}$ aerodynamic diameter is less than or equal to $20 \%$ across the center two-thirds of the sampling plane. 


\subsection{Scale-Model Testing Criteria}

The ANSI/HPS N13.1 - 1999 standard contains acceptance criteria for the use of a similarly designed stack, including a scale-model, as a substitute for the actual stack (Section 5.2.2.2 of ANSI/HPS N13.1 1999). The acceptance criteria are summarized as follows:

1) The scale model and its sampling location must be geometrically similar to the actual stack, with components influencing contaminant mixing and velocity profile proportional in the scale model proportional to those in the actual stack.

2) The scale model's mean velocity times hydraulic diameter must be within a factor of six of the actual stack. The stack diameter of the scale model must be at least $250 \mathrm{~mm}$ at the sampling location. The Reynold's number for the prototype and scale model stacks must be greater than 10,000 .

The scale model results are considered valid if:

3) The velocity profile in the actual stack meets the uniformity criterion, and

4) The difference between velocity COVs of the two systems is not more than $5 \%$.

5) The sampling location is placed at a geometrically similar location in the actual and scale model stacks. 


\subsection{Results}

PNNL conducted tests on two R\&D facilities to evaluate the radionuclide airborne sampling systems against criteria in ANSI/HPS N13.1 - 1999 Sampling and Monitoring Releases of Airborne Radioactive Substances from the Stacks and Ducts of Nuclear Facilities. These tests were conducted from 2000 to 2002 and included sampling system inspections, probe cleaning, and sampling system location tests for cyclonic flow, uniform velocity of stack gas, gas tracer uniformity, and particle tracer uniformity. Results are discussed for each of the facilities evaluated.

The two R\&D facilities are on opposite ends of a spectrum with regard to accessibility of sampling systems and relative ease of conducting the activities. The RPL sampling system is part of a bundled manifold that is extremely heavy and located in the stack eighty feet off the ground. Removal of the system for cleaning would require a crane and counter-weight apparatus for balance. In addition, the RPL is considered a "nuclear facility" as determined by Hazard Categorization and Accident Analysis Techniques for Compliance with DOE Order 5480.23 Nuclear Safety Analysis Reports (US DOE, 1997). This DOE order applies additional controls and oversight on any work conducted in or around the building. For these reasons, a scale model of the RPL stack was used to test sampling system location. In contrast, the 331 Building sampling system is located on the roof of the building in a relatively easily accessible location and the building is not considered a "nuclear facility" with the additional safety concerns associated with that classification. Thus, the 331 Building was the first to be evaluated and will be discussed first in this Section.

\subsection{Evaluation of the 331 Life Sciences Laboratory I}

Evaluation activities for the 331 Building include remote camera inspection of the 331 Building radionuclide air sampling system, subsequent probe washing, and field tests conducted at the 331 main stack sampling location to determine whether the current site would meet criteria in ANSI/HPS N13.1 1999.

\subsubsection{Inspection and Cleaning of 331 Sampling System}

The radionuclide air sampling system for the 331 Building was designed to meet ANSI N13.1 1969 with a multi-nozzle probe operated isokinetically and located eight duct diameters downstream and two duct diameters upstream of the nearest flow disturbance. The system was installed in the early 1990s and is located on the roof of the building in a horizontal length of 6.5 feet diameter circular duct. The 331 roof is easily accessible via a passage way leading up from the third floor. The sample cabinet is also 
located on the roof in close proximity to the sampling system, alleviating the need for a long sample transport line.

The inspection was performed with a videoscope, originally designed for the medical industry, containing a camera chip at the tip of a $10 \mathrm{~mm}$ diameter, $9 \mathrm{~m}$ long cable. The videoscope was inserted into the sampling system at the point of the collection filter and moved up through the manifold to each of the nozzle locations. Air-driven articulation in the videoscope moved the camera tip allowing some viewing movement. Deposition in the sampling system was expected to be minor because HEPA filters are located downstream of all laboratory operations and upstream of the sampling system, reducing the size of particles in the exhaust stream.

Contrary to expectations, deposition could be seen in the bottom half of the horizontal part of the manifold and in some cases small amounts opposite the nozzle opening. Figure 7 shows the deposition, which appears as a light color in the photo. The picture is slightly askew due to a slight twist in the camera tip. The nozzle opening should come from the exact middle left side of the pipe. The layer of deposition was thick enough and sufficiently loose that small furrows were formed as the camera cable was extracted, as shown in Figure 8. Smears were taken of this material and appeared as a very fine dark substance similar to graphite powder (see Figure 9). No radioactivity was detected in the smears or throughout the inspection process.

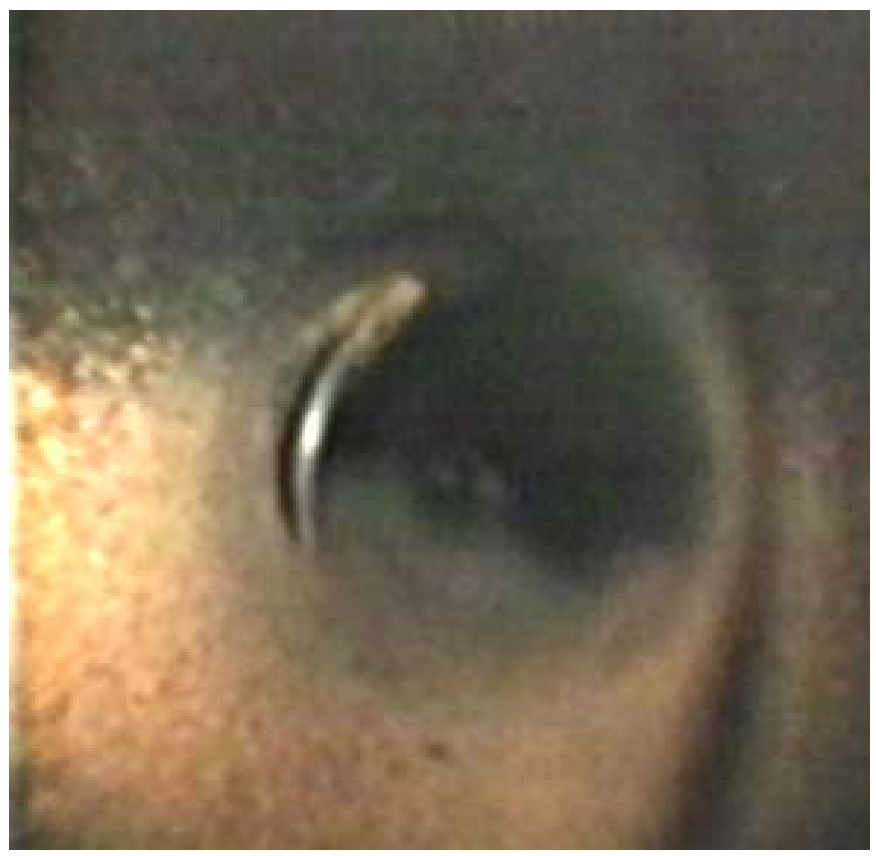

Figure 7. Inside of 331 Radionuclide Air Sampling System Manifold 


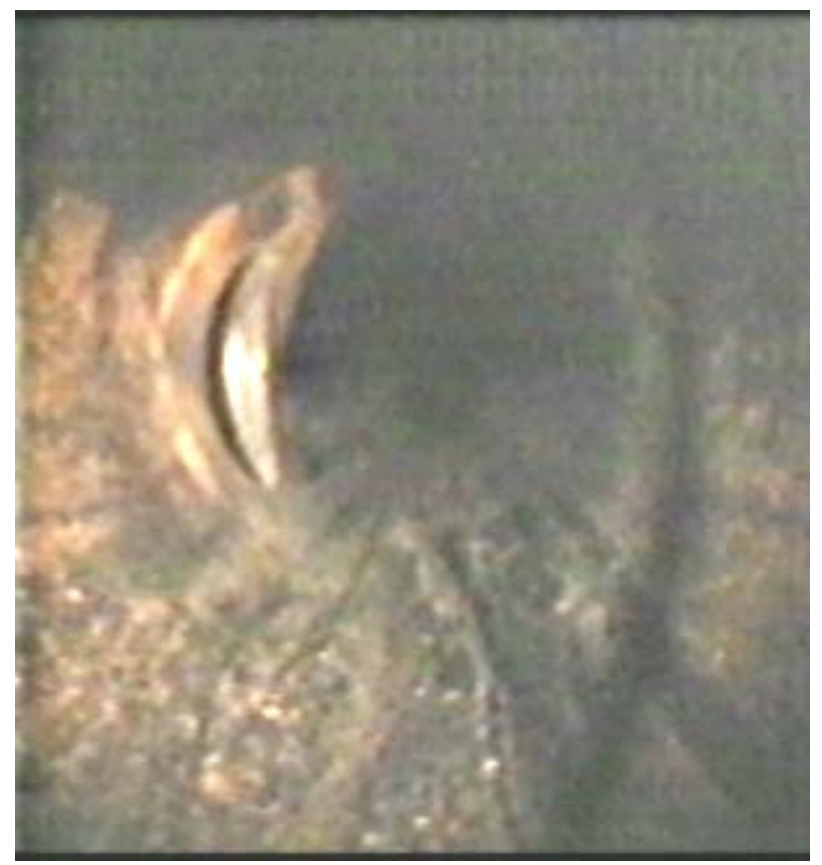

Figure 8. Furrows in Deposition

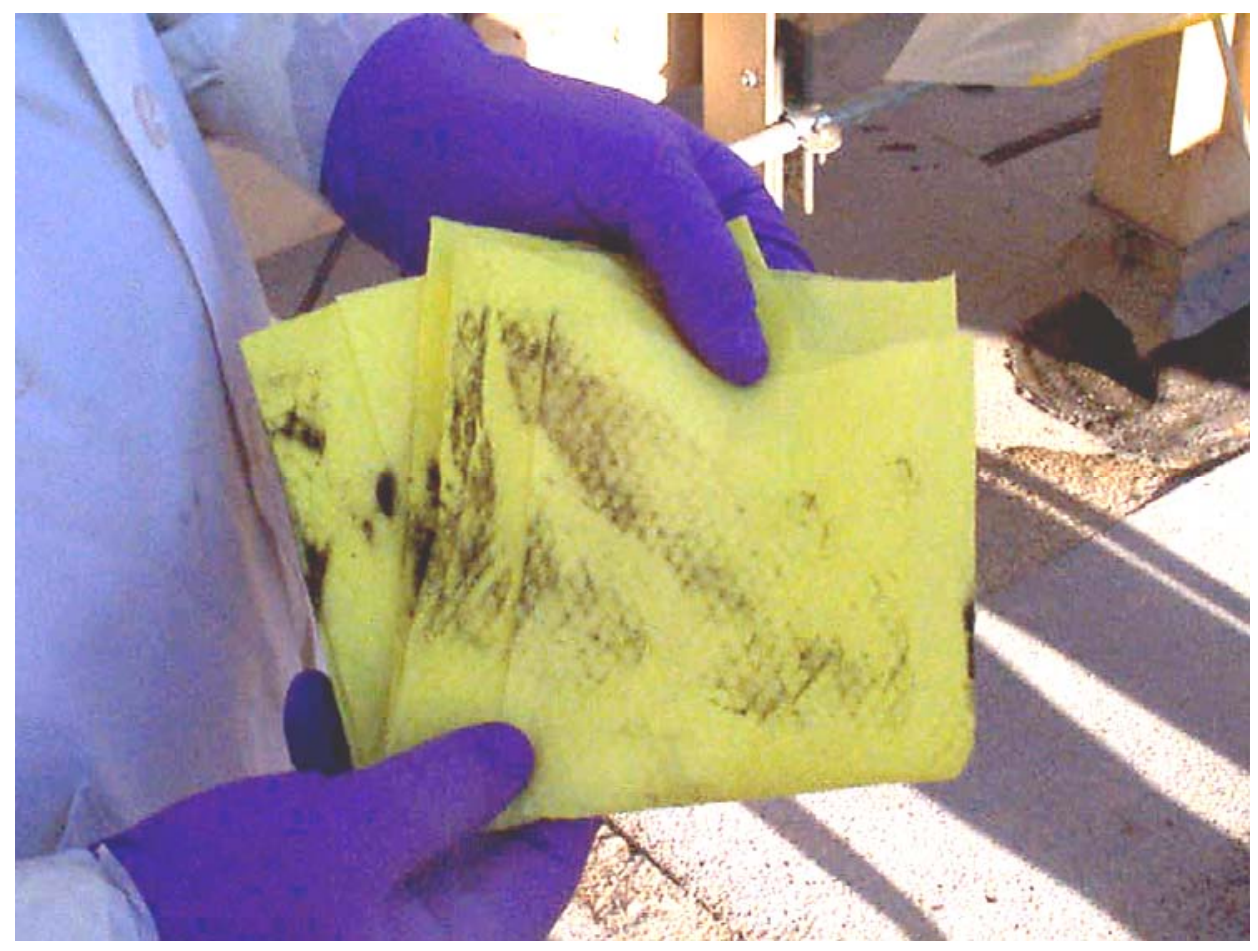

Figure 9. Smear of Material Deposited in 331 Sampling System 
The articulation in the camera tip was not sufficient to see the nozzle openings, so a mirror attachment was secured to the end of the camera and the cable was moved up through the manifold a second time. The nozzles appeared to be unblocked and little deposition was detected in the nozzle interior although the lighting and mirror reflection did not offer a clear image (see Figure 10).

Although the visual deposition over the approximately ten years of sampler operation was a thin layer, the amount was still larger than expected given the HEPA-filtered controls. The following speculations were offered on possible sources of the material:

- Deposition may have been present at the time of installation; no inspections were performed at that time.

- A facility modification project in the mid-1990's routed unfiltered exhaust from construction areas to the main stack for several months, possibly contributing to the deposited material.

- A large common plenum is present just downstream of the final HEPA filters. Dust may have accumulated in the plenum and become resuspended before entering the final duct.

To obtain additional characterization data, smear material was taken to an analytical laboratory and viewed with a Scanning Electron Microscope (SEM) to obtain information on particle size and shape. In addition, Energy Dispersive Spectrometry (EDS) was used to indicate some of the elements present in the material. Figure 11 shows that smear particles had a quartz-like shape and ranged in size from less than a micron to over 20 microns. Figure 12 shows elements of some particles identified using EDS. The elements included several metals ( $\mathrm{Al}, \mathrm{Mg}, \mathrm{Fe}, \mathrm{Zn})$ and silicon and did not imply any particular source.

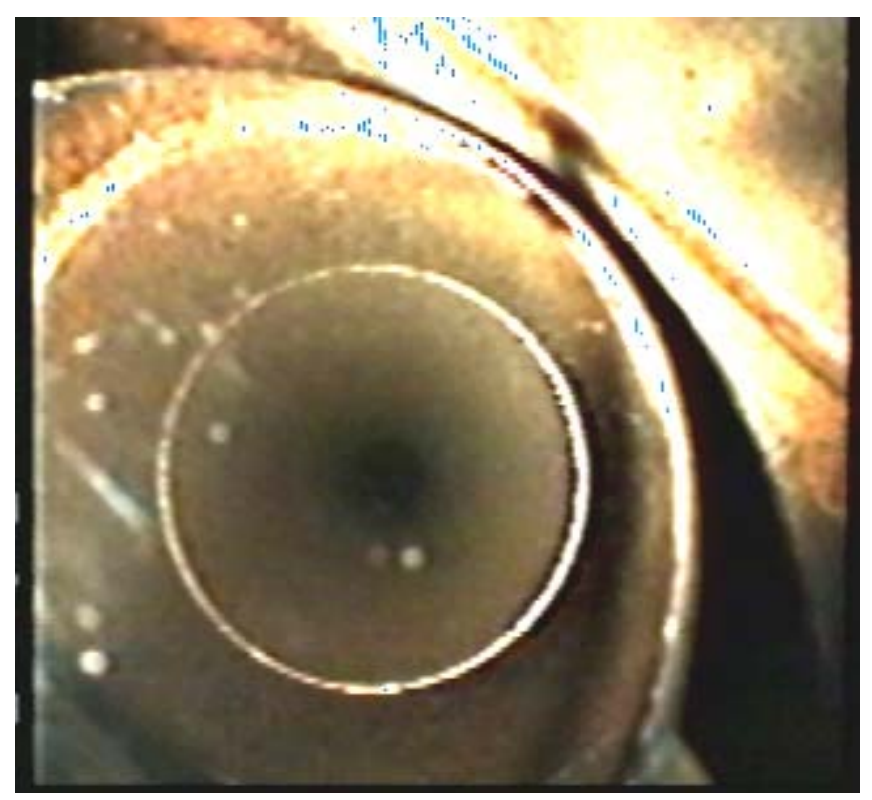

Figure 10. Interior of Nozzle 


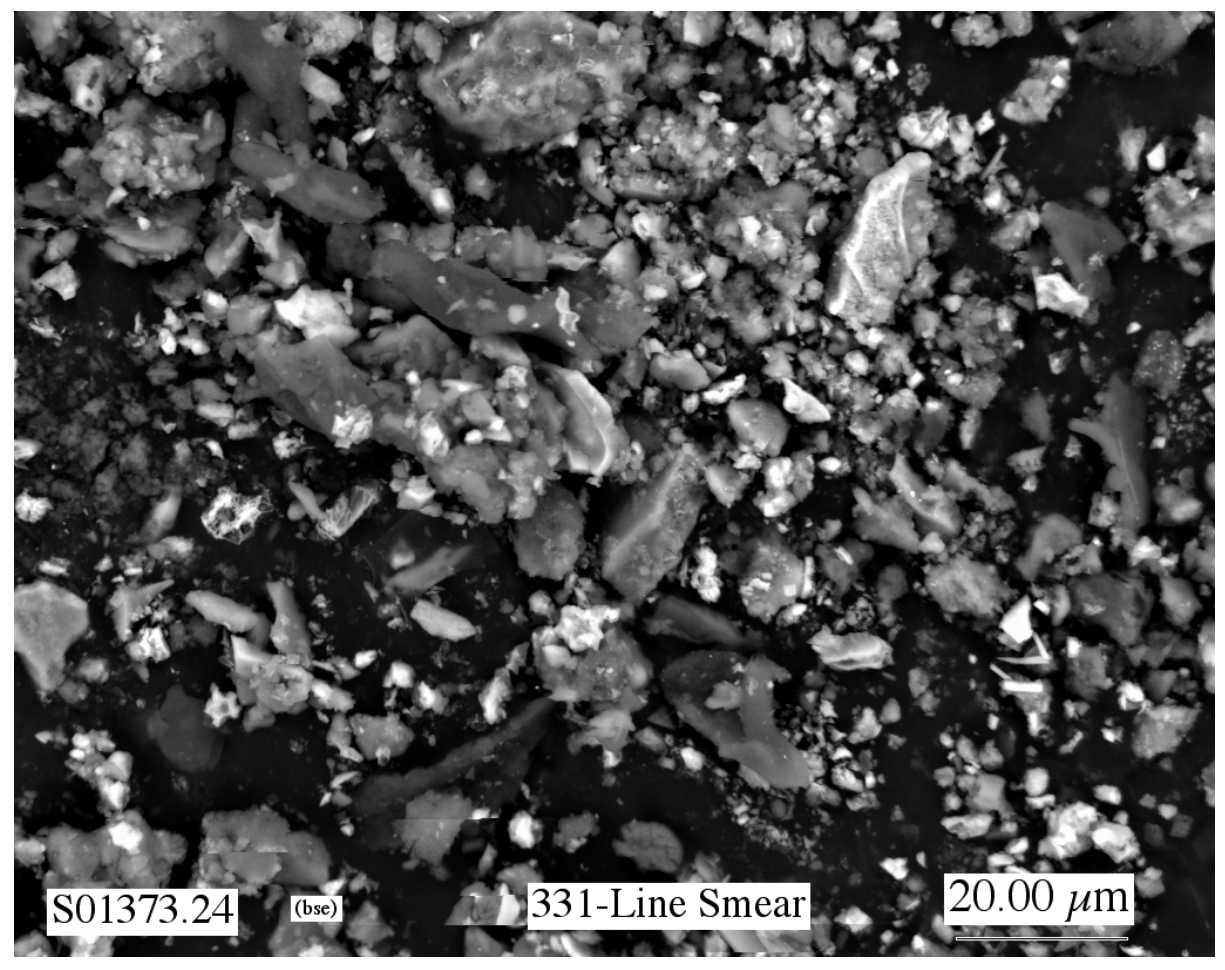

Figure 11. Scanning Electron Microscope Photograph of Smear Material



Figure 12. Energy Dispersive Spectrometry Analysis 
The maintenance requirements in ANSI/HPS N13.1 - 1999 call for an annual inspection of the sample systems followed by cleaning if deposits are visible. No criteria are given for the term "visible," but the amount of material seen in the 331 sampling system was believed to merit cleaning. Procedures were developed and cleaning of the system was performed in 2002. ${ }^{5}$ The 331 sampling manifold was disconnected and moved to a scaffolding platform set up on the roof nearby. The heavy manifold was shifted onto the scaffolding using a rope guide for support and direction. Deposition was noted on the outside upstream side of the sampling system as would be expected from particle impaction. The material was fine and not easily wiped off; some scrubbing was required. Frequent checks were made for radioactivity throughout the cleaning process but no activity above background was detected.

The interior of the probe was cleaned with bristle brushes and de-ionized water. Cleaning was aided by the use of a videoscope camera that helped determine cleaning effectiveness and verify cleanliness of the interior before re-connecting and restarting the system. About one liter of wash water was sufficient for the process and showed visible dirt when cleaning was completed. The wash water was submitted for analysis to determine radiological content and total solids (suspended plus dissolved solids). Analytical results showed no detectable radioactivity. About $277 \mathrm{mg}$ of total solids were collected in the wash water; approximately half of the mass was suspended and half dissolved. Based on this analysis, the average loading over the entire interior surface area of the sampling manifold was calculated as $1.5 \mathrm{~g} / \mathrm{m}^{2}$. Most of the material was deposited in the bottom half of the piping, so actual loading was probably closer to $3 \mathrm{~g} / \mathrm{m}^{2}$. ANSI/HPS N13.1 - 1999 requires non-HEPA-filtered systems to be cleaned when deposited material exceeds $1 \mathrm{~g} / \mathrm{m}^{2}$. Although the 331 system is HEPA-filtered and thus not subject to this requirement, the loading data gives a perspective to the number in the standard.

Probe washing operations were conducted over about a half-day time period and required the assistance of a number of support personnel (e.g. power operators and an electrician to connect and disconnect the system, a radiological control technician to perform the washing and periodically check for radioactivity). Cost impacts are discussed in Section 5.4.

\subsubsection{Evaluation of 331 Sampling Location}

Field tests were performed in 2000 to determine whether the current sampling location for the 331 Building radionuclide air sampling system would meet requirements in ANSI/HPS N13.1 - 1999. These

\footnotetext{
${ }^{5}$ Oak Ridge National Laboratory (ORNL) has cleaned sampling systems on the Oak Ridge Site for many years and their experiences and procedures proved useful in this activity. However, ORNL went through considerable effort to install systems to enable probe cleaning operations and even have redundant systems that can be swapped out for cleaning in some cases.
} 
tests were conducted at the sampling location and included a velocity profile test, cyclonic flow test, and gas tracer uniformity tests.

Velocity profiles are performed quarterly at the 331 sampling location by Facility Operations airbalance staff and one of these traverses was used as data for this project. The traverse was performed using a standard pitot tube and a slant-tube manometer. The minimum number of traverse points is twelve for the measurement location, which meets the measurement site selection criterion of 40 CFR 60, Appendix A, Reference Method 1 (eight duct-diameters downstream and two duct-diameters upstream from any flow disturbance). However, a 20-point traverse was selected to exceed the minimum ${ }^{6}$ with ten points measured horizontally and ten vertically in the horizontal duct. The acceptance criterion for uniform velocity is that the Coefficient of Variation (COV) shall not exceed $20 \%$ over the center region of the stack that encompasses at least two-thirds of the stack area. The results in Table 1 show a COV of 7\% which meets the criteria.

Table 1. Results of Velocity Profile Test

\begin{tabular}{|l|c|c|c|}
\hline & $\begin{array}{c}\text { Vertical 10-Point } \\
\text { Traverse }\end{array}$ & $\begin{array}{c}\text { Horizontal 10-Point } \\
\text { Traverse }\end{array}$ & All Traverse Points \\
\hline Mean Velocity, ft/min & 2073 & 2060 & 2067 \\
\hline Standard Deviation, $\mathrm{ft} / \mathrm{min}$ & 147 & 156 & 145 \\
\hline COV, $\%$ & 7 & 8 & 7 \\
\hline
\end{tabular}

The cyclonic flow test was also performed using a 20-point traverse and methods as described in Section 4.2.1. The traverse was repeated three times to evaluate data repeatability. The results showed some cyclonic flow, particularly in the upper west corner of the duct. However, the cyclonic tendencies were not severe enough to fail the sampling site. The acceptance criteria were met and the average airvelocity angle (average of absolute values) deviated from the axis of the sampling nozzle by $11.6^{\circ}$, within the $20^{\circ}$ criteria. Table 2 is a summary of the data.

The gas tracer uniformity test was performed according to the method described in Section 4.2.3. Sulfur hexafluoride was used as a tracer gas and injected into the exhaust stream immediately downstream of an axial booster fan (extreme left end of the horizontal duct pictured in Figure 5). Tracer gas was injected at five positions within the cross section of the duct at this location. These positions were:

- Center

- 15 inches $^{7}$ from the bottom wall of the duct

- 15 inches from the top wall of the duct

\footnotetext{
${ }^{6}$ Air-balance staff perform velocity traverses on all PNNL final exhaust systems that are sampled for radioactive airborne particles and has standardized this operation to a 20-point traverse that exceeds the minimum for all measurement locations.
} 
- 15 inches from west side wall of the duct

- 15 inches from the east side wall of the duct

Table 2. Cyclonic Flow Data for 331 Building

\begin{tabular}{|c|c|c|c|}
\hline Traverse Point & $\begin{array}{c}\text { Vertical } \\
\text { Average Angle, } \\
\text { Degrees }\end{array}$ & $\begin{array}{c}\text { Horizontal } \\
\text { Average Angle, } \\
\text { Degrees }\end{array}$ & $\begin{array}{c}\text { Overall } \\
\text { Average Angle, } \\
\text { Degrees }\end{array}$ \\
\hline 1 & 22.7 & 18.3 & 20.5 \\
\hline 2 & 29.7 & 23.3 & 26.5 \\
\hline 3 & 30.0 & 20.7 & 25.3 \\
\hline 4 & 19.3 & 17.3 & 18.3 \\
\hline 5 & 11.0 & 8.0 & 9.5 \\
\hline Center & 6.0 & 3.3 & 4.7 \\
\hline 6 & 1.3 & 0.3 & 0.8 \\
\hline 7 & -2.7 & -3.0 & -2.8 \\
\hline 8 & -5.3 & -5.0 & -5.2 \\
\hline 9 & -5.7 & -6.7 & -6.2 \\
\hline 10 & -6.0 & -8.7 & -7.3 \\
\hline $\begin{array}{c}\text { Average of } \\
\text { absolute value }\end{array}$ & 12.7 & 10.4 & 11.6 \\
\hline
\end{tabular}

Tracer gas concentrations of around $1 \mathrm{ppm}$ were measured at the sampling location, about fifty feet downstream of the injection point. Concentrations were measured at each of the 20 traverse points used for the other tests and traverses were repeated three times to evaluate data repeatability. The injection position that resulted in the worst mixing was repeated. The acceptance criteria for this test are two-fold:

- The COV shall not exceed $20 \%$ over the center region of the stack that encompasses at least two-thirds of the stack area

- The maximum value of tracer gas concentration shall not exceed the mean value by more than $30 \%$ at any point on a complete set of velocity traverse points ( $\%$ maximum deviation $\leq 30 \%)$.

A summary of the results are shown in Table 3 and indicate that the 331 system did not pass the gas tracer uniformity test. Only two of the six traverses had a COV $\leq 20 \%$ and none of the traverses had a \% maximum deviation of $\leq 30 \%$.

Table 3. Results of 331 Building Gas Tracer Uniformity Tests

\begin{tabular}{|c|c|c|}
\hline Gas Tracer Injection Position & Coefficient of Variance, $\%$ & Maximum Deviation from Mean, $\%$ \\
\hline Center & 19 & -49 \\
\hline West & 35 & 89 \\
\hline East & 16 & 50 \\
\hline Top & 22 & -54 \\
\hline Bottom & 39 & 70 \\
\hline Bottom (repeat) & 39 & -59 \\
\hline
\end{tabular}

\footnotetext{
${ }^{7}$ The injection point must be within $20 \%$ of the diameter or within 15.6 inches of the duct wall for the 78 -
} inch diameter duct. 
Figure 13 shows the concentration profile of the tracer gas with injection at the center position. Higher concentrations were measured in the top and west quadrants of the duct at the sampling location.

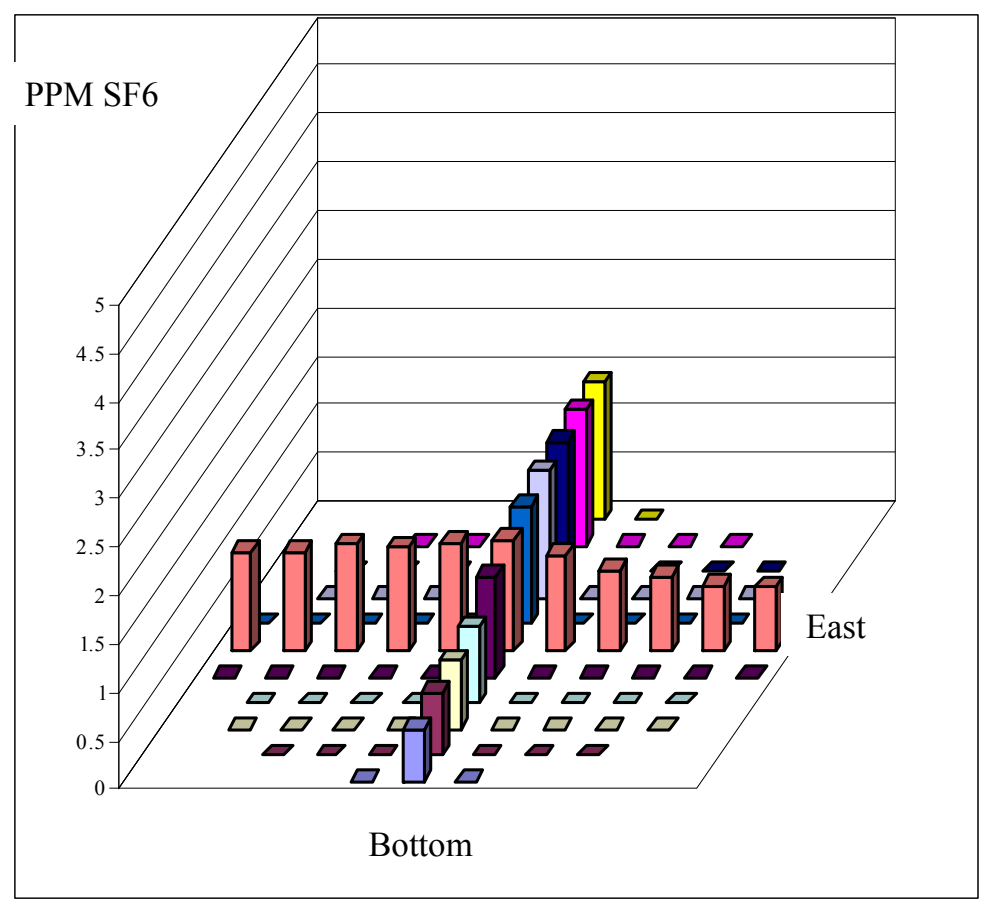

Figure 13. Tracer Gas Profile in the 331 Facility Duct

A second series of tests were run with the axial booster fan speed elevated to determine if this would enhance mixing. Only the worst-case configuration was tested, injecting into the bottom of the duct and taking a horizontal traverse, for the varying fan speed settings. The results (see Table 4) indicate some improvement at the highest exhaust flows, but not enough to pass the test.

Table 4. Results of Boosting Stack Flow on Gas Tracer Uniformity

\begin{tabular}{|c|c|c|}
\hline Exhaust Flow, cfm & Coefficient of Variance, $\%$ & Maximum Deviation from Mean, $\%$ \\
\hline 68,000 & $44-52$ & $58-83$ \\
\hline 69,500 & 43 & 91 \\
\hline 70,000 & 28 & 59 \\
\hline 74,000 & 28 & 39 \\
\hline 80,000 & 24 & 50 \\
\hline
\end{tabular}

In the aerosol uniformity test, a 10 micron particle stream must be injected at a location downstream of disturbances such as feeder ducts, fans, and air pollution control equipment and the concentration of particles at the sampling system are measured to determine concentration uniformity. The acceptance criterion is that the COV shall not exceed $20 \%$ over the center region of the stack that encompasses at least 
two-thirds of the stack area. After the 331 system failed to pass the gas tracer uniformity test, the decision was made to evaluate fan effects rather than conduct the aerosol test. Thus, the aerosol uniformity test was not conducted.

The current sampling system for the 331 main stack does not pass the tracer gas test in the ANSI/HPS N13.1 - 1999 standard. Sources of radioactive emissions in the building are primarily from hoods and glove boxes located far upstream of the location where the tracer gas was injected and it is probable that mixing from source to sample point is much greater than indicated with the test; tracer gas injection limitations may be too conservative in representing actual mixing of the 331 facility exhaust system. Possible options for the 331 building sampling system if required to meet ANSI/HPS N13.1 1999 in the future are:

- Reposition the sampling system further downstream in the horizontal duct. The sampling system is about two duct diameters upstream of a $90^{\circ}$ bend (this was required under the old standard) leading to the main stack. It is possible that moving the sampling system the two additional duct diameters downstream to just before the bend could improve mixing enough to pass the ANSI/HPS N13.1 - 1999 standard.

- Remove the axial booster fan. This would allow injection of the tracer gas and aerosol further upstream and allow for additional mixing.

- Enhance mixing in the horizontal duct through use of an air blender device such as that described at www.airblender.com.

A computational fluid dynamics (CFD) code (see Section 5.3) may be a useful aid in exploring these and other options.

\subsection{Evaluation of the Radiochemical Processing Laboratory}

Evaluation activities for the RPL include an inspection of the RPL radionuclide air sampling system using a remote camera and tests conducted on a scale-model replica of the RPL final exhaust system to determine whether the current sampling site would meet criteria in ANSI/HPS N13.1 - 1999. The scale model evaluation also included use of a CFD code to predict results.

\subsubsection{Inspection of Sampling System}

The radionuclide air sampling system in the RPL is located eighty feet above the ground in the main stack. This location makes it difficult to access for inspections or other maintenance activities although a ladder and platform have been provided (see Figure 2). The air sampling and monitoring manifold bundle is also extremely heavy and not conducive to easy removal for cleaning activities; removal for cleaning 
would require the use of a crane and counterweight balances to lift and lower the manifold to a cleaning site. The system was installed in the early 1990s.

An inspection was performed in 2002 during a facility outage using a videoscope similar to that used for the 331 sampling system. The inspection included visual observation of the outside of the sampling nozzles, interior of the sampling manifold, and as much of the transport line as the 30 -foot cable could reach including sections immediately upstream of the manifold and downstream of the sample filter.

The outside of the nozzles was inspected by attaching the camera cable to a rod and inserting the rod through ports used for velocity traverse measurements. With an exhaust flow of $140,000 \mathrm{cfm}$, the velocity in the 8-foot diameter stack is about $2800 \mathrm{ft} / \mathrm{min}$, making it somewhat difficult to maintain a steady position to view the nozzle openings. However, views were obtained and Figure 14 shows a typical sight of the outside of one of the RPL nozzles. Deposition was expected to be minimal because of the HEPA filtration just upstream of the final fans. As expected, little deposition was noted on the outside of the nozzles. Without a clear definition of "visible" in ANSI/HPS N13.1 - 1999, it is difficult to determine whether the small amount of deposition shown would be enough to negate the need for further inspection of the sampling system interior and/or cleaning.

To perform the interior inspection, the sampling system was disconnected close to the stack wall and the camera cable inserted first up through the manifold and then down through the transport line. The manifold inspection showed small amounts of deposition, but less than that evident in the 331 inspection. The transport line was even cleaner, particularly the vertical length where it is more difficult for material to build up. Figures 15 and 16 show different views of the inspection. Radiological control support was used throughout the inspection to look for the presence of radioactive materials collected on surfaces. No detectable radioactivity was found. 


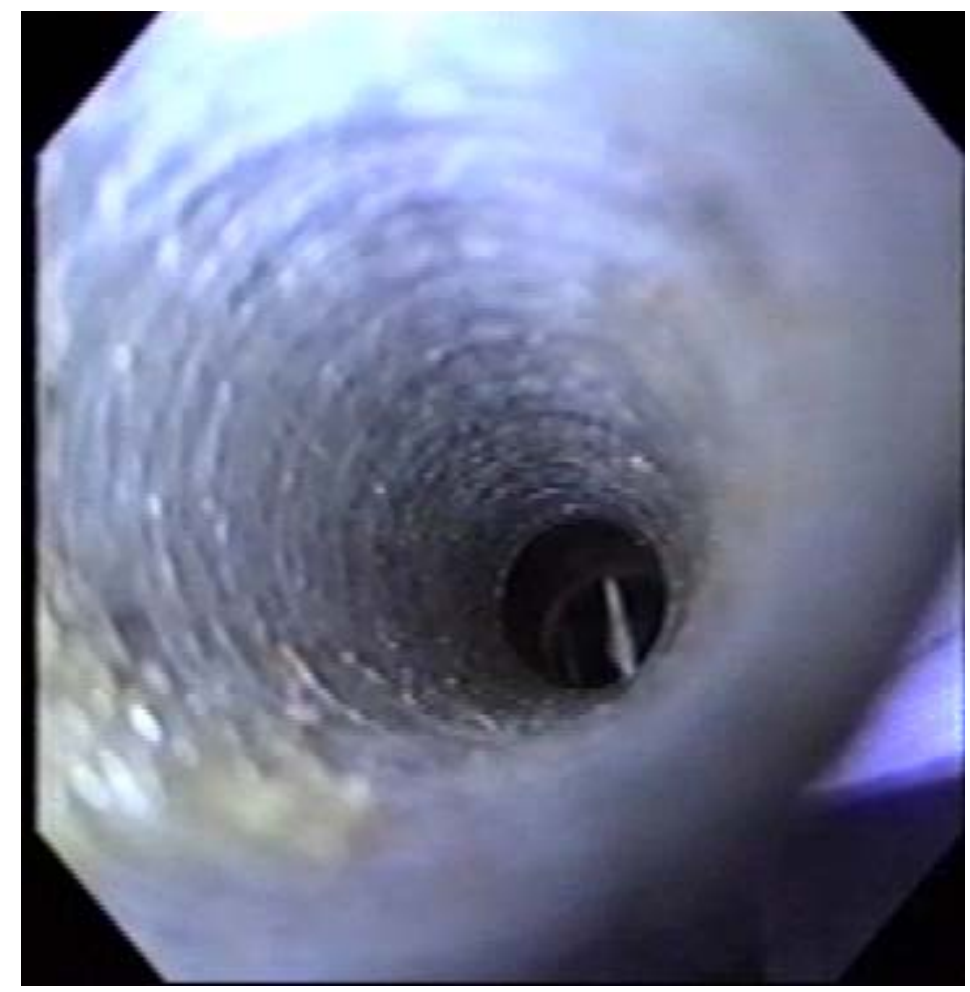

Figure 14. View of Outside of Nozzle

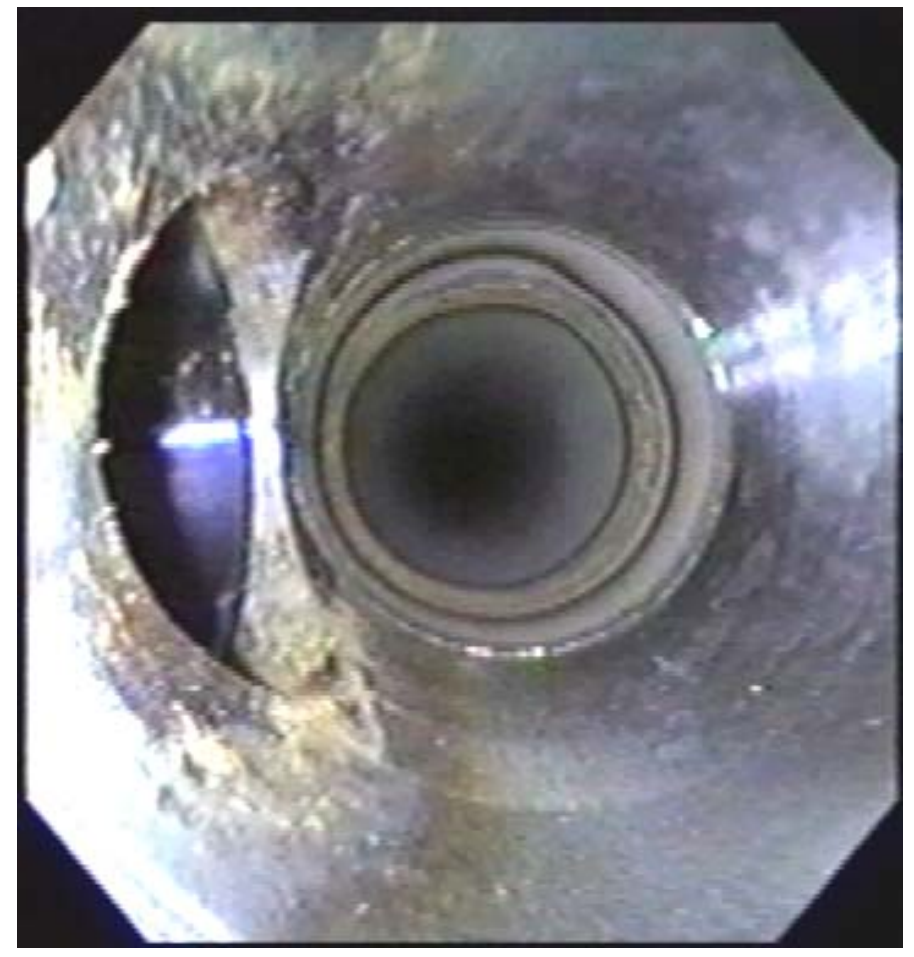

Figure 15. View of Inside of RPL Sample Nozzles 


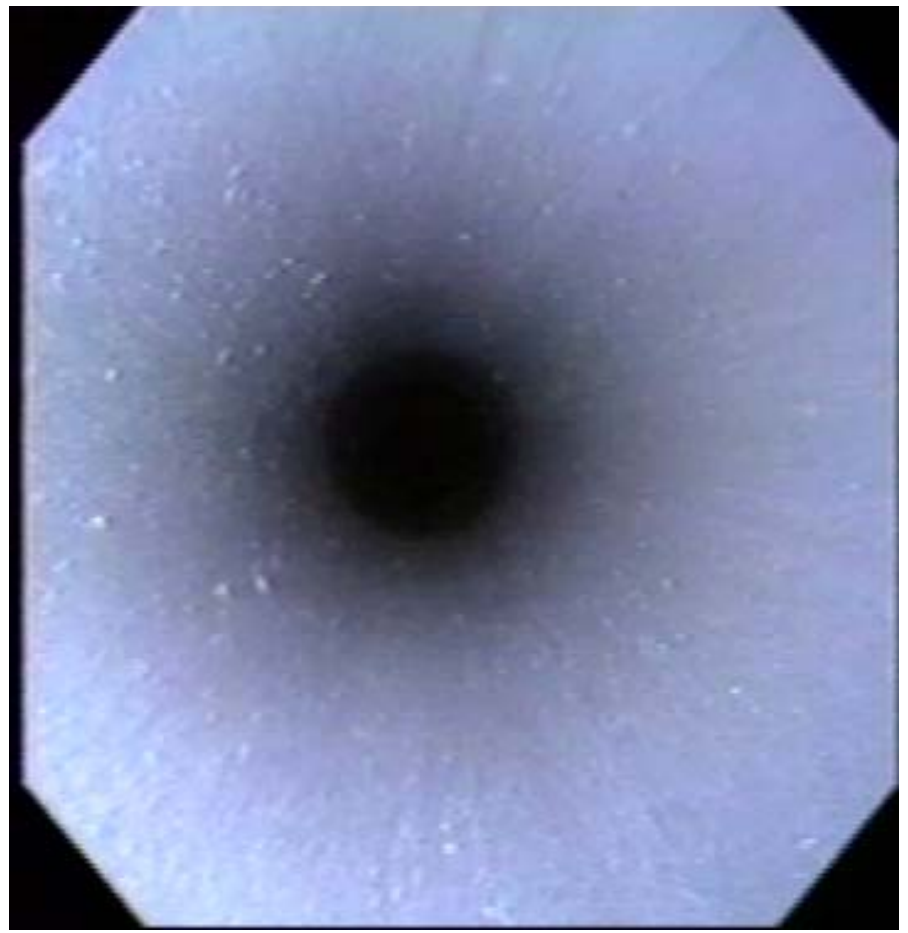

Figure 16. View of Inside of RPL Vertical Transport Line

The remainder of the inspection was performed at the collection filter cabinet. The particulate sample filter was disconnected and the videoscope was extended up the transport line as far as it could reach. This end of the approximately 60 -foot long transport line was expected to be the cleanest end and this expectation was corroborated by the videoscope inspection with very little deposition found.

The deposition appears to be minor throughout the RPL sampling system, but it remains to be seen whether the results of this inspection will excuse the facility from probe cleaning operations. As previously discussed, the term "visible" used in ANSI/HPS N13.1 - 1999 is not well defined and optical cameras can magnify particles that would not normally be visible to the naked eye. Probe cleaning is a concern for the RPL system because of its elevation and the weight of the manifold bundle. Cleaning of this system would be much more expensive than for the 331 Building, possibly by an order of magnitude. Also, a facility outage would likely be required for the RPL because of the extra time needed to remove and re-install the system.

\subsubsection{Evaluation of RPL Sampling Location}

The RPL is PNNL's most significant facility for radionuclide airborne sampling and monitoring and is the most likely facility to be subject to ANSI/HPS N13.1 - 1999 requirements in the future. Evaluation of the current sampling system location was performed to consider options and impacts of this 
eventuality. The decision was made to evaluate the RPL sampling location using a scale model because of the difficulty in taking measurements at the 80-foot level, the additional controls needed to conduct the work in a "Nuclear" facility, and the potential impact on facility operations. The scale model testing criteria discussed in Section 4.3 were used to design the prototype. The portion of the RPL exhaust system containing the final exhaust fans, downstream ducting, and stack were considered a sufficient segment to adequately model velocity and contaminant mixing. Physical dimensions of these components were field verified and converted using the selected scale. Several scales were proposed that fit the following three criteria:

- mean velocity times hydraulic diameter of scale model must be within a factor of six of actual stack

- $\quad$ scale model stack diameter must be at least $250 \mathrm{~mm}$ at the sampling location

- the Reynold's number for both scale model and actual stack must be greater than 10,000.

A scale of 1:5.33 was selected based on convenient stack and duct size (the scale model stack would be 18feet high and 18-inches in diameter), and similarity of stack velocity. A drawing of the scale model is provided in Figure 17.

The scale model was built by PNNL crafts personnel and assembled on an outside concrete pad using scaffolding as support for the stack section. Four variable speed fans were connected to the scale model in a configuration geometrically similar to the actual stack. Fans were numbered sequentially with Fan 1 farthest and Fan 4 closest to the stack. The RPL normally operates only three of the four fans and alternates the standby fan. Therefore, a similar arrangement was used in the testing with Fan 2 placed in standby.

Initial measurements were made to calibrate the variable speed fans and identify the power setting for the desired velocities. In addition to modeling current stack velocity, additional measurements modeling a higher stack velocity were included in anticipation of a potential project to upgrade the RPL exhaust fans.

Velocity uniformity tests were run at two fan speeds: one reflecting current operations and another showing the effects of a higher exhaust flow. Traverses were performed using a standard pitot tube and a slant-tube manometer. To comply with 40 CFR 60, Appendix A, Reference Method 1, a 16-point traverse was used for all measurements with eight points measured in the east-west direction and eight in the northsouth direction of the vertical duct. Traverses were performed in triplicate to determine data repeatability and each set of traverses were conducted twice. The acceptance criterion for uniform velocity is that the Coefficient of Variation (COV) shall not exceed 20\% over the center region of the stack that encompasses at least two-thirds of the stack area. The results are summarized in Table 5 showing a COV of less than $3 \%$ in all cases, meeting the criteria and thus passing this test. 

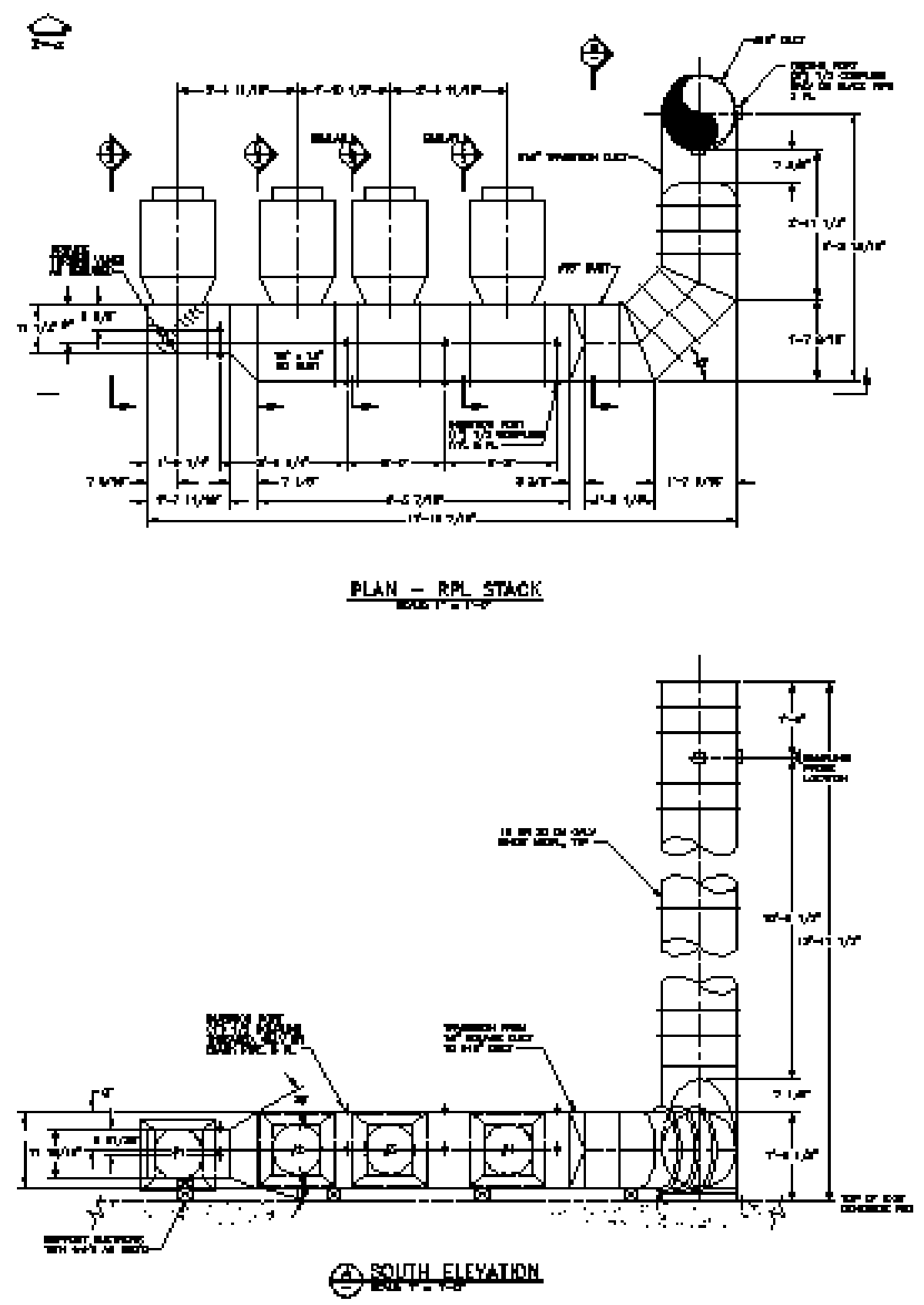

Figure 17. Scale Model of RPL Final Exhaust System 
Table 5. Velocity Profile Test Results for RPL Prototype

\begin{tabular}{|l|c|c|c|c|}
\hline & $\begin{array}{c}\text { Model } \\
\text { Current } \\
\text { RPL Exhaust }\end{array}$ & $\begin{array}{c}\text { Model } \\
\text { Current } \\
\text { RPL Exhaust } \\
\text { Repeat }\end{array}$ & $\begin{array}{c}\text { Model } \\
\text { Higher } \\
\text { RPL Exhaust }\end{array}$ & $\begin{array}{c}\text { Model } \\
\text { Higher } \\
\text { RPL Exhaust } \\
\text { Repeat }\end{array}$ \\
\hline Mean Velocity, ft/min & 2530 & 2491 & 3378 & 3367 \\
\hline Standard Deviation, ft/min & 56.1 & 70.4 & 54.6 & 90.5 \\
\hline COV, \% & 2.2 & 2.8 & 1.6 & 2.7 \\
\hline
\end{tabular}

The velocity uniformity of the prototype must be close to that of the actual stack to show that it appropriately models existing conditions. Velocity traverses are performed quarterly on the RPL stack to determine exhaust flow; the three most recent traverses were used as a comparison with scale model results. The COV of the actual stack traverses ranged from $3.6 \%-4.4 \%$. The difference between the scale model and actual stack traverses was about $2 \% \mathrm{COV}$, well within the criteria $5 \%$.

The cyclonic flow test was also performed at two exhaust flows using a 16-point traverse and methods as described in Section 4.2.1. As with the velocity uniformity tests, traverses were performed in triplicate and two sets were performed at each fan speed. The results are presented in Table 6. Some cyclonic flow was noted at some of the far walls, but almost all individual traverse points were within the $20^{\circ}$ criteria and on an average, the air-velocity angle was only $6^{\circ}-7^{\circ}$. The sampling location passed the test for cyclonic flow.

Table 6. Cyclonic Flow Data for RPL Stack Prototype

\begin{tabular}{|c|c|}
\hline Test & $\begin{array}{c}\text { Average of Absolute Value } \\
\text { Degrees }\end{array}$ \\
\hline Current RPL Exhaust Flow & 7.0 \\
\hline Current RPL Exhaust Flow Repeat & 6.5 \\
\hline High RPL Exhaust Flow & 7.4 \\
\hline High RPL Exhaust Flow Repeat & 6.4 \\
\hline
\end{tabular}

The gas tracer uniformity test was performed according to the method described in Section 4.2.3. Ports were installed in several locations in the duct downstream of the fans so that different injection locations could be explored if resources allowed. The injection location where mixing is expected to be least is just downstream of the fan closest to the stack (Fan 1 in Figure 18). This location was chosen for most of the gas tracer uniformity tests although a few tests were also conducted with the tracer gas injected at the far right port (downstream of Fan 4) in Figure 18.

Sulfur hexafluoride was used as a tracer gas and injected at five positions within the cross section of the duct at the port location. These positions were:

- Center

- North top corner (within 3.6 inches of wall) 
- South top corner

- North bottom corner

- South bottom corner

Tests were run for two exhaust flows: one modeling current RPL conditions, and another at higher flows in anticipation of a possible fan upgrade. Concentrations were measured at each of the 16 traverse points used for the other tests and each traverse was repeated three times for data repeatability. In addition, the injection port at Fan 4 was also tested by injecting the tracer gas in the center of the duct. The acceptance criteria for this test are two-fold:

- The COV shall not exceed $20 \%$ over the center region of the stack that encompasses at least two-thirds of the stack area.

- The maximum value of tracer gas concentration shall not exceed the mean value by more than $30 \%$ at any point on a complete set of velocity traverse points ( $\%$ maximum deviation $\leq 30 \%$ ).

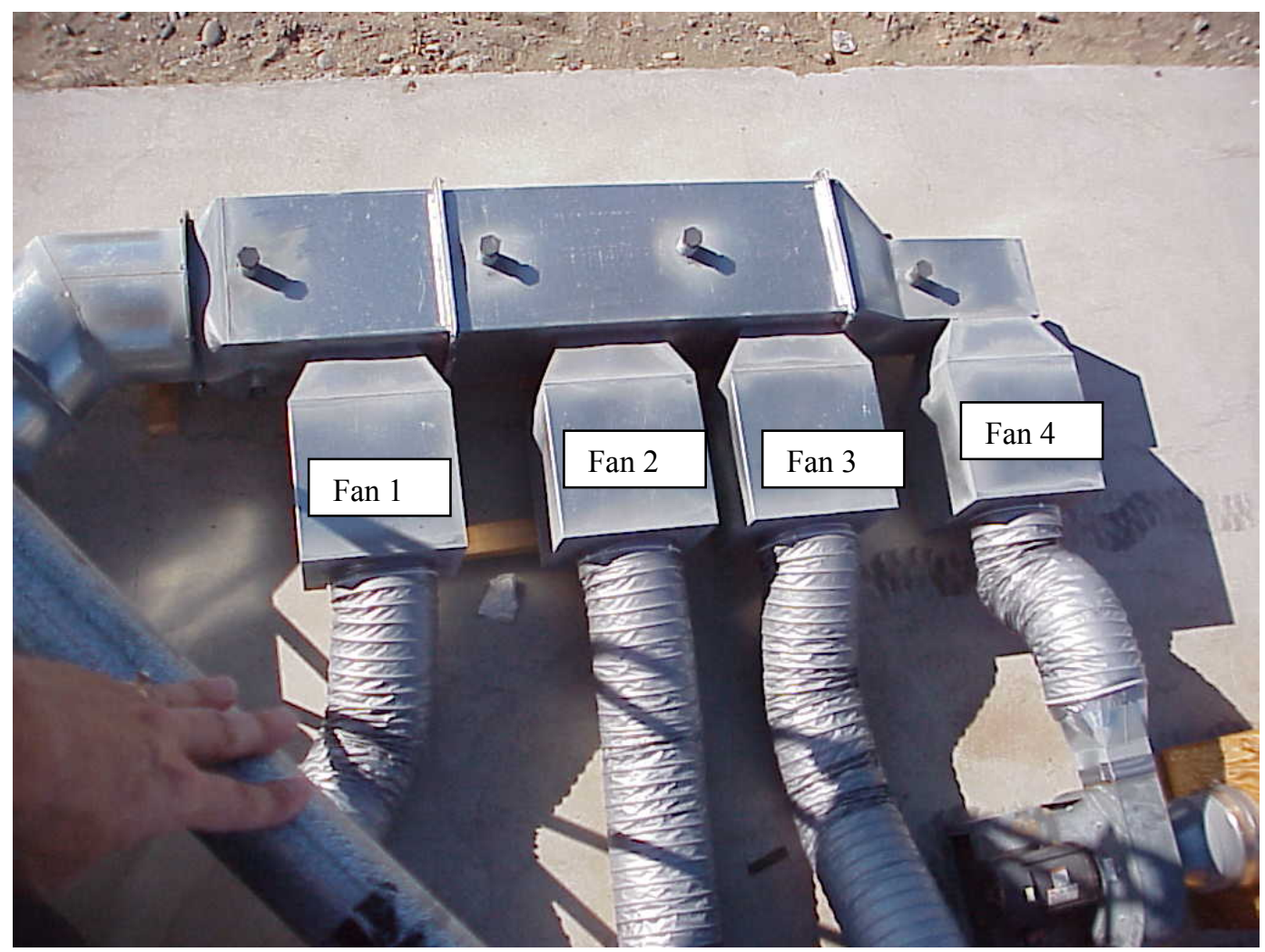

Figure 18. Injection Locations for Gas and Aerosol Tracer Tests

A summary of the results are shown in Table 7 and indicate that the sampling location passed the gas tracer uniformity test. All of the twelve traverses had a COV $\leq 7 \%$ and maximum deviation from the mean 
of $\leq 12 \%$. An unexpected result was that higher stack flow did not correspond to better mixing of the tracer gas. Injections at Fan 4 appeared to be better mix than those at Fan 1, most likely because the tracer gas has farther to travel before reaching the sampling location and thus has more time to mix.

Table 7. Results of 331 Building Gas Tracer Uniformity Tests

\begin{tabular}{|c|c|c|c|c|}
\hline Gas Tracer Injection Position & \multicolumn{2}{|c|}{ Model Current RPL Flow } & \multicolumn{2}{c|}{ Model High RPL Flow } \\
\cline { 2 - 5 } & COV \% & $\begin{array}{c}\text { Max Dev } \\
\text { From Mean \% }\end{array}$ & COV \% & $\begin{array}{c}\text { Max Dev } \\
\text { From Mean \% }\end{array}$ \\
\hline Center & 5 & 9.3 & 5 & 9.4 \\
\hline North Top & 2 & 4.0 & 7 & 11.4 \\
\hline South Top & 2 & 3.9 & 4 & 11.6 \\
\hline North Bottom & 2 & 3.0 & 5 & 7.7 \\
\hline South Bottom & 2 & 3.4 & 3 & 5.1 \\
\hline Center - Injection at Fan 4 & 1 & 1.4 & 2 & 3.5 \\
\hline
\end{tabular}

In the aerosol uniformity test, an oil mist was injected at selected locations in the center of the duct. A total of five tests were conducted so that both flow conditions (current RPL flow and higher potential future flow) and two injection locations (downstream of fans 1 and 4) could be explored. The fifth test was a repeat of the worst case from the first four.

The acceptance criterion is that the COV shall not exceed $20 \%$ over the center region of the stack that encompasses at least two-thirds of the stack area. All test conditions passed the test; the COV ranged from $4.6 \%-11 \%$ for both flow conditions and injection locations tested. Figure 19 shows a typical aerosol concentration profile; concentrations were slightly higher on the east side of the duct at the measurement location.

Table 8. RPL Model Stack Aerosol Test Results

\begin{tabular}{|c|c|c|}
\hline Injection Point & $\begin{array}{c}\text { Model Current RPL Flow } \\
\text { COV \% }\end{array}$ & $\begin{array}{c}\text { Model High RPL Flow } \\
\text { COV \% }\end{array}$ \\
\hline Center - Fan 1 & 4.6 & 5.3 \\
\hline Center - Fan 4 & 6.9 & 11.0 \\
\hline Center - Fan 4 & & 4.8 \\
\hline
\end{tabular}

\subsection{CFD Modeling}

The series of tests verified that the current sampling location at RPL meets criteria in the revised ANSI/HPS N13.1 - 1999 standard. If building operations are required to comply with ANSI/HPS N13.1 1999, the data obtained could be used to show that the current sampling location has adequate mixing and velocity uniformity for single-point sampling and an ANSI/HPS N13.1 - 1999 compliant sampling system could be installed at this location. However, this location is 80 feet above the ground and a more desirable location for operations would be at ground level. To explore the mixing at other locations, the code STAR$\mathrm{CD}$ was used to electronically model the prototype stack. A grid was developed to match the prototype 
design (see Figures 20 and 21) resulting in over 1.2 million computational cells. The code was used to show velocity flow patterns throughout the system and to predict test results. Figure 22 shows the flow and concentration effects predicted by the code.



Figure 19. Tracer Aerosol Profile in the 325 Facility Proto-type Stack 
A comparison of test results versus STAR-CD predictions is shown in Table 9. The code was close to predicting velocity uniformity but underpredicted cyclonic flow. Gas tracer uniformity predictions were within the measured range for a simulation of injection at Fan 1, but did not predict the improved mixing with injection at Fan 4 that was obtained through actual measurements. The prediction for aerosol uniformity was slightly under-predicted.

Table 9. Comparison of CFD Predictions with Measured Values

\begin{tabular}{|l|c|c|}
\hline Test & Scale Model Measurements & STAR-CD Prediction \\
\hline Velocity Uniformity, COV \% & $2.2-2.8$ & 1.9 \\
\hline Cyclonic Flow, Angle in Degrees & $6.5-7.0$ & $<1$ \\
\hline $\begin{array}{l}\text { Gas Tracer Uniformity } \\
\text { Inject at Fan 1, COV \% }\end{array}$ & $2-5$ & 4.8 \\
\hline $\begin{array}{l}\text { Gas Tracer Uniformity } \\
\text { Inject at Fan 4, COV \% }\end{array}$ & 2 & 16.3 \\
\hline $\begin{array}{l}\text { Aerosol Uniformity } \\
\text { Inject at Fan 1, COV \% }\end{array}$ & 4.6 & 3.3 \\
\hline
\end{tabular}

CFD modeling was implemented at the end of the testing period and insufficient resources were available to test the code as needed to validate its use in predicting mixing. However, use of the CFD code was helpful in determining that the base of the stack would not likely meet mixing criteria and it is likely to be useful in the future as a design tool or to model existing stacks before performing the more costly measurement.

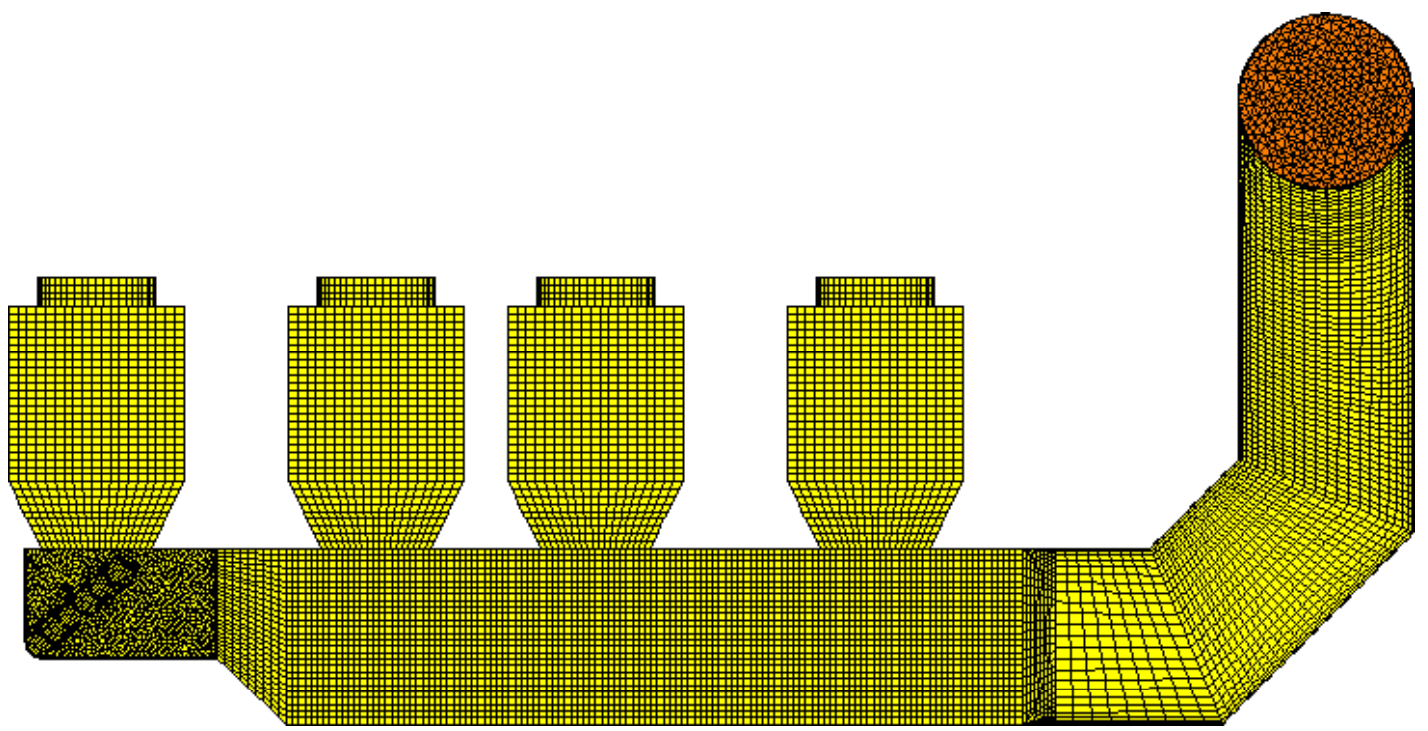

Figure 20. Top-Down View of STAR-CD Grid 


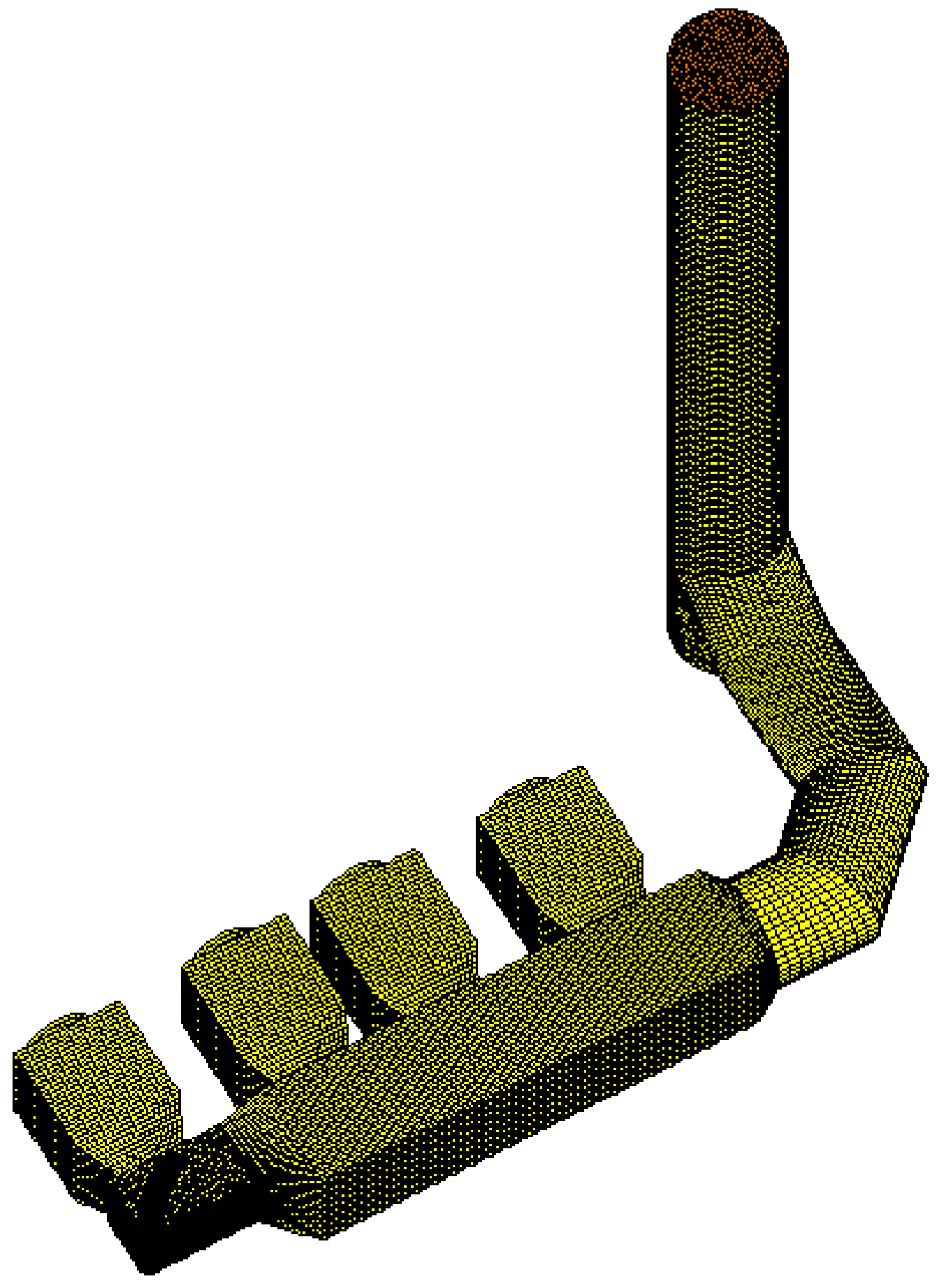

Figure 21. Isometric View of STAR-CD Grid 


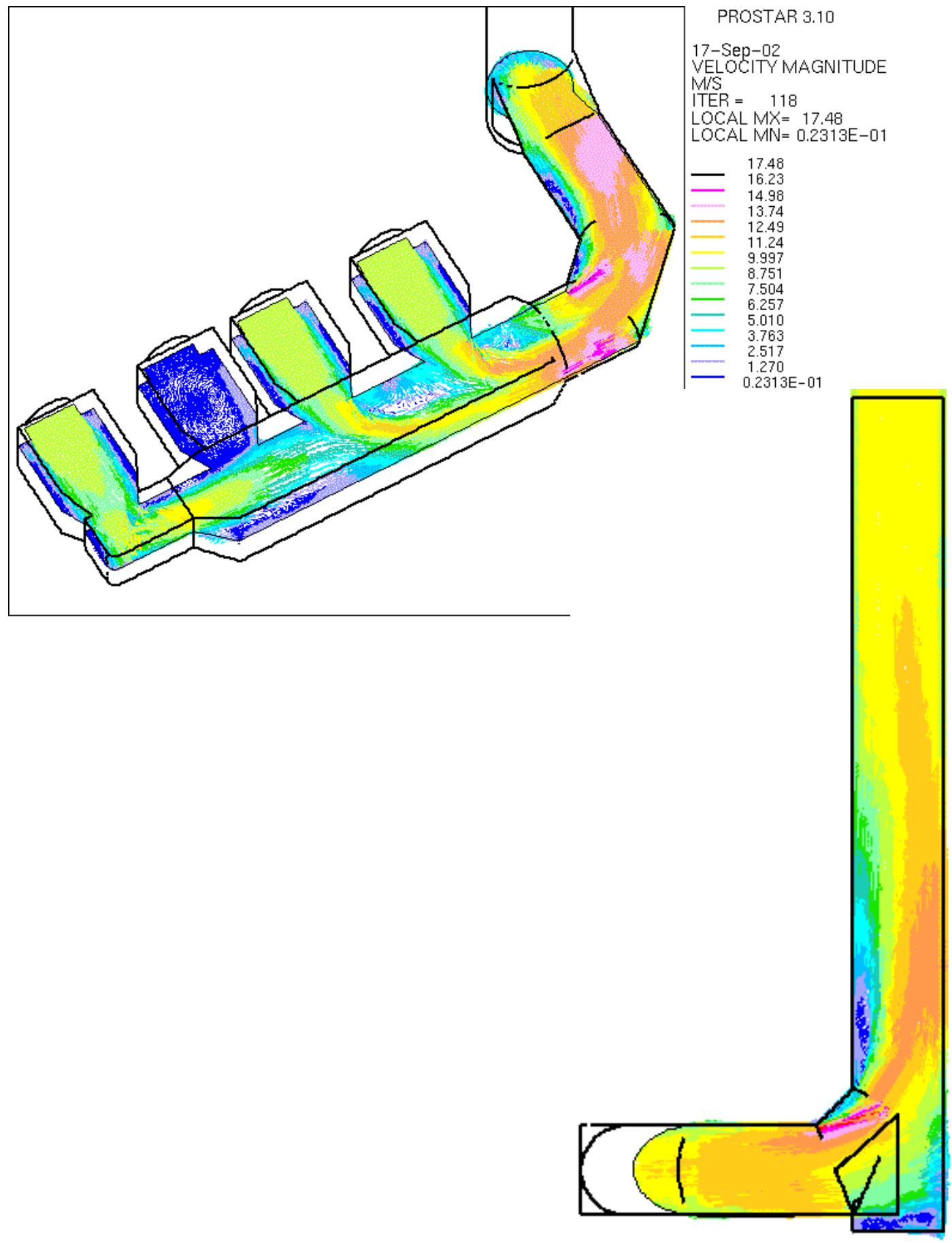

Figure 22. Flow Dynamics Predicted by STAR-CD

(Shades given for different velocities, so the well-mixed regions are those with few or no shade variations.) 


\subsection{Cost Impacts}

Cost of videoscope inspections are relatively minor, particularly if the system is easily accessible and has short transport lines as was the case with the 331 Building. The inspection at the RPL was more costly because access to the system at the 80 -foot level required more planning and training. RPL also required more controls because of its "nuclear" facility status and the activity had to be performed off-shift during a coordinated facility outage. An estimate of costs for each of the activities is provided in Table 10 .

Probe cleaning costs at the 331 Building included a site visit to ORNL, planning and coordination, development of a procedure, funding for a number of support personnel, and analysis. If probe cleaning is required in the future, the costs are expected to be less, benefiting from much up-front work and experience garnered in this initial effort. Future probe cleanings at the 331 Building could possibly be performed for $\$ 10 \mathrm{~K}$, depending on analysis requested.

The tests required to qualify the sampling location per ANSI/HPS N13.1 - 1999 criteria are by far the most expensive activities undertaken. These costs ranged from $\$ 50 \mathrm{~K}$ for the 331 Building to over $\$ 100 \mathrm{~K}$ for the RPL. Also, future costs will be incurred for the 331 Building if the revised standard is applied because the sampling location did not successfully test out. CFD models may be a relatively inexpensive way to explore potential sampling locations before running the actual tests. It should be noted that the sampling location tests are one-time costs only whereas inspection and cleaning are required on a periodic basis.

Table 10. Costs for Evaluation Activities

\begin{tabular}{|l|l|}
\hline Activity & Approximate Cost \\
\hline 331 Videoscope Inspection & $\$ 12 \mathrm{~K}$ \\
\hline 331 Probe Cleaning & $\$ 25 \mathrm{~K}$ \\
\hline 331 Field Tests of Sample Location & $\$ 50 \mathrm{~K}$ \\
\hline RPL Videoscope Inspection & $\$ 15 \mathrm{~K}$ \\
\hline RPL Scale Model Tests of Sample Location & $\$ 120 \mathrm{~K}$ \\
\hline CFD Modeling & $\$ 10 \mathrm{~K}$ \\
\hline
\end{tabular}




\subsection{Conclusions}

Based on the evaluation activities documented here, it can be concluded that the impacts of ANSI/HPS N13.1 - 1999 requirements on existing stack sampling systems will vary considerably depending on facility-specific parameters such as accessibility of sampling system, configuration of system (e.g. size, weight, length of transport line), and building operations and classification. For the buildings evaluated, inspections could be performed with a videoscope camera although not all of the RPL sampling system could be viewed because the camera cable was not long enough to extend clear through the transport line.

The benefit of annual inspections required by the revised standard may also be questionable for some facilities. The two facilities both had HEPA-filtered systems and did not show any nozzle blockage or enough build-up in the sampling systems to degrade the capability of the sampler in capturing aerosol. Even with many years of operation, deposition was light in the sampling systems inspected. Perhaps frequency can be negotiated with regulatory agencies given sufficient inspection evidence. Also, even with HEPA-filtered systems, particles in the exhaust stream can oftentimes be ten micron or larger. Whether or not this size is associated with radioactive particles is most likely dependent on the facility.

The term "visible" deposition in the revised standard needs clarification. Even minor deposits may be visible with videoscope technology currently available. The particle loading information obtained from the 331 probe cleaning activity shows what an average loading level of $>1 \mathrm{~g} / \mathrm{m}^{2}$ might look like. This loading is noticeable but not great enough to significantly impact sampling and much less than that needed to block nozzles.

While inspections may be relatively easily accomplished, probe washing may be a difficult and

costly task for existing systems. If washing is needed, it may be more cost effective to replace the sampling system with one that can be removed or swapped out as experienced by the ORNL site. However, this strategy will have to take into account the likelihood of being required to upgrade to an ANSI/HPS N13.1 1999 compliant system with the associated costs of identifying and documenting a suitable sampling location.

Sampling system location that prior to the revised standard was dictated by ideally locating the system 8 diameters downstream and 2 diameters upstream of disturbances will not necessarily have the mixing characteristics required by the revised ANSI/HPS N13.1 - 1999 standard. A CFD code may help determine whether the existing sampling location is likely to test successfully or in identifying a new location if this probability is low. Use of the code may help reduce costs in the long term by helping to 
pinpoint locations before the more expensive testing begins. The code may also help with design of sampling systems in new facilities.

Use of a scale model may be helpful for facilities where testing of the actual sampling location would be burdensome or difficult. A scale model would also allow for easier exploration of alternate sampling locations. However, consideration must be taken to ensure that the scale model meets criteria in the revised standard so that the test data are valid for the actual system.

The evaluation activities described in this paper can be used to estimate impacts to these and other facilities and to identify elements of the revised standard that need additional clarification. Because inspections are required annually, subsequent inspections of the 331 Building can help determine whether the deposition washed from the probe was due to a one-time source of emissions (e.g. the period of construction when unfiltered emissions were routed to the final exhaust duct) or whether this type of deposition can be expected routinely. A follow-up probe wash of the 331 Building one year after the first probe wash could provide data to estimate annual emissions and possibly back-calculate particle size.

Another future activity that could provide great benefits to facilities required to apply the revised standard is continued development and validation of the CFD code. If the code is shown to accurately predict mixing characteristics in exhaust systems, then it could be used to design new systems, retrofit old systems, and ensure that scale models have the features necessary to adequately reflect full-scale exhaust systems.

A third area that will require future efforts is development of sampling system leak tests. These tests are now required annually for major emission points. Although some guidance on a graded approach is provided in the revised standard, the specifics on how to implement this requirement have yet to be developed. 


\section{Bibliography}

ANSI. 1969. Guide to Sampling Airborne Radioactive Materials in Nuclear Facilities, ANSI N13.1-1969. American National Standards Institute

ANSI. 1999. Sampling and Monitoring Releases of Airborne Radioactive Substances From the Stacks and Ducts of Nuclear Facilities, ANSI/HPS N13.1 - 1999. American National Standards Institute

Ballinger, MY. 2001. Facility Effluent Monitoring Plan for the 325 Radiochemical Processing Laboratory. PNNL-12157, Rev. 1, Pacific Northwest National Laboratory, Richland, Washington.

Ballinger, MY. 2002. Facility Effluent Monitoring Plan for the 331 Complex. PNNL-12158, Rev. 1, Pacific Northwest National Laboratory, Richland, Washington.

Ballinger, MY, MJ Sula, TL Gervais, KD Shields, and DL Edwards. 2001. Assessment of Unabated Facility Emission Potentials for Evaluating Airborne Radionuclide Monitoring Requirements at Pacific Northwest National Laboratory - 2001, PNL-10855 Rev. 2 AD-902, Pacific Northwest National Laboratory, Richland, Washington.

Gerber, MS. 1992. Past Practices Technical Characterization Study - 300 Area - Hanford Site. WHC-MR0388, UC-702, Westinghouse Hanford Company, Richland Washington.

Rokkan, DJ, LP Diediker, DL Dyekman, NA Homan, K Rhoads, and LH Staven. 2002. Radionuclide Air Emission Report for the Hanford Site, Calendar Year 2001, DOE/RL-2002-20, Revision 0, United States Department of Energy, Richland, Washington.

U.S. Department of Energy. 1997. Hazard Categorization and Accident Analysis Techniques for Compliance with DOE Order 5480.23 Nuclear Safety Analysis Reports. DOE-STD-1027-92, Change Notice No. 1, U.S. Department of Energy, Washington, D.C.

U.S. Environmental Protection Agency (EPA). 1990. National Emission Standards for Hazardous Air Pollutants. 40 CFR 61. Environmental Protection Agency, U.S. Code of Federal Regulations. 1990.

U.S. Environmental Protection Agency (EPA). 1996. Sample and Velocity Traverses For Stationary Sources. 40 CFR 60, Appendix A, Method 1. Environmental Protection Agency, U.S. Code of Federal Regulations. 1996.

WAC 1994. Radiation Protection - Air Emissions, WAC 246-247, Washington Administrative Code. Washington Department of Health.

WDOE 2001. Hanford Site Air Operating Permit, \#00-05-006. Washington State Department of Ecology. 